
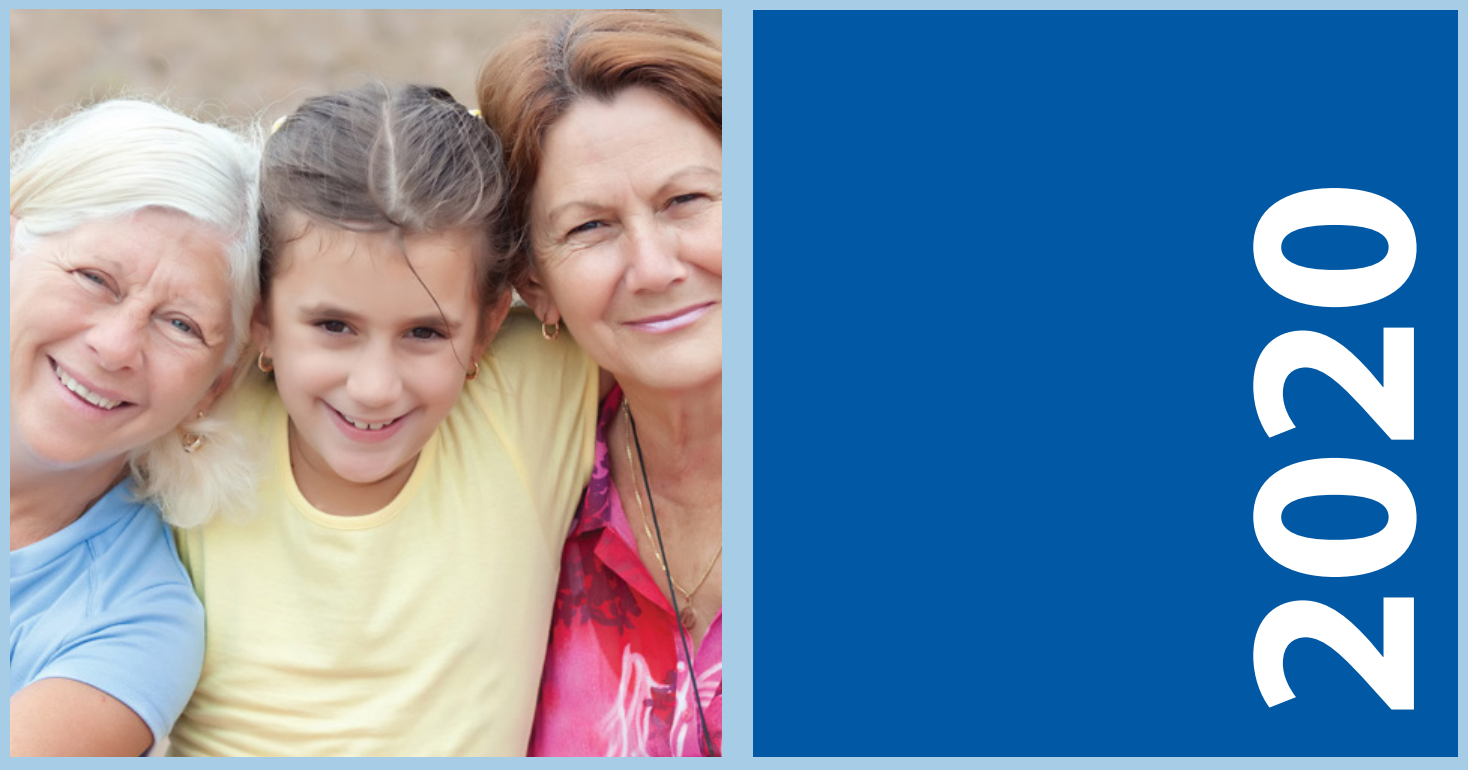

Receipt of care and caring in community-dwelling adults aged 50 years and over in Ireland

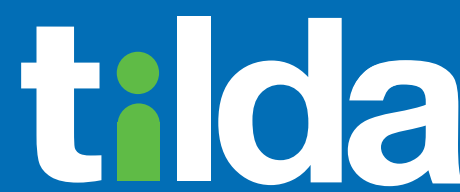

Staidéar Fadaimseartha na hÉireann um Dhul in Aois

The Irish Longitudinal Study on Ageing 


\section{Receipt of care and caring in community-dwelling adults aged 50 years and over in Ireland}

Christine McGarrigle and Rose Anne Kenny

The Irish Longitudinal Study on Ageing, Trinity College Dublin.

On behalf of the TILDA team

November 2020 
Copyright (c) The Irish Longitudinal Study on Ageing 2020

The Irish Longitudinal Study on Ageing

Trinity College Dublin

Dublin 2

Tel: +35318962509

Email: tilda@tcd.ie

Website: www.tilda.ie

ISBN: 978-1-907894-33-6

https://doi.org/10.38018/TildaRe.2020-09 


\section{Acknowledgements}

We would like to acknowledge the vision and commitment of our study funders, the Department of Health, the Health Research Board, Science Foundation Ireland, The Atlantic Philanthropies, and Irish Life plc. We would like to state that any views expressed in this report are not necessarily those of the Department of Health or of the Minister for Health. We would also like to thank the TILDA participants without whom this research would not be possible. 


\section{Contents}

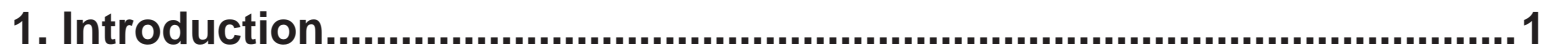

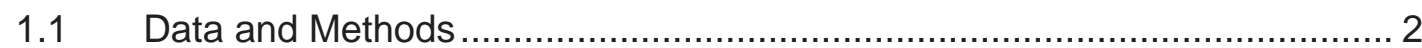

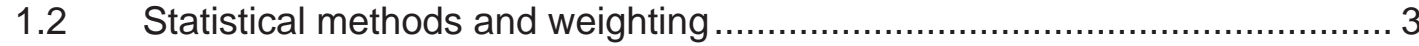

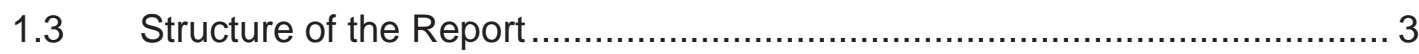

2. Prevalence of functional disability and receipt of care ...................... 4

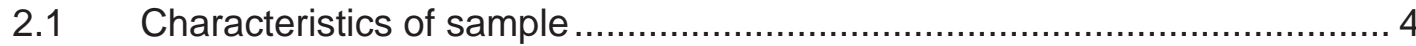

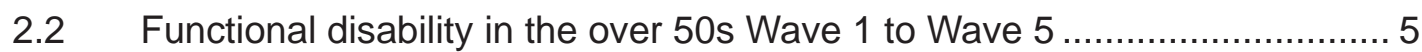

2.3 Receipt of help with functional limitations............................................. 7

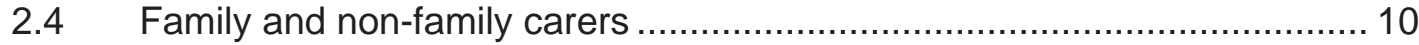

2.5 Receipt of state and private-provided home support by disability status ... 12

2.6 Unmet need for help with ADLS and IADLS Wave 5............................ 16

3. Prevalence of caring in the older population in Ireland.....................18

3.1 Caring by demographic characteristics .............................................. 18

3.2 Numbers of hours of caring provided ................................................. 21

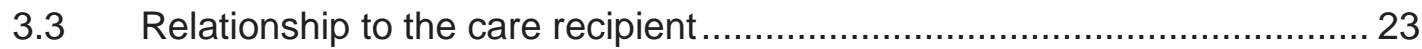

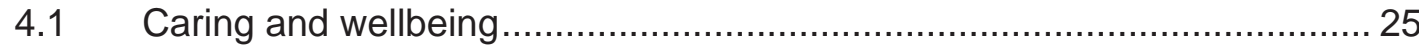

4. Family caring and the health of carers ….........................................25

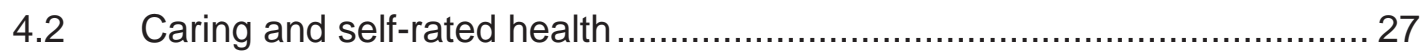

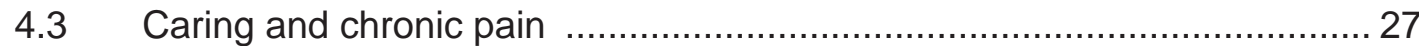

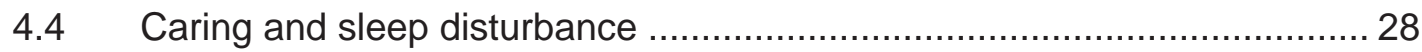

4.5 Caring and hypertension ................................................................... 30

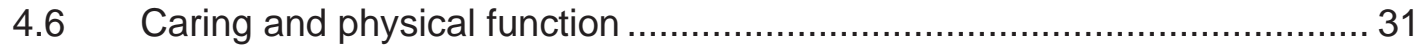

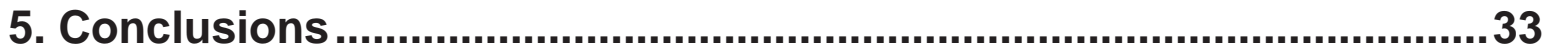

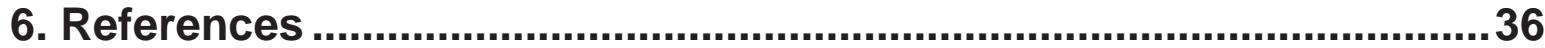




\section{Key Findings}

- One in eight (13\%) adults aged over 50 report a functional limitation. This is a combination of limitations in instrumental activities of daily living (IADL) (difficulty with cooking, cleaning and grocery shopping for example) and basic functional activities (ADL) (difficulty with dressing, eating and bathing).

- Help received with functional limitations by the older population is from a mixture of family carers and formal care, either state-provided or privately sourced care. Overall, the proportion who received any help (including both family caring and home support) increased from $45 \%$ receiving help with ADL and IADL limitations in Wave 1, to $60 \%$ in Wave 5.

- The majority of that help was provided by family carers (70\%), with $30 \%$ receiving either state-provided or private home support in Wave 5 (2018).

- For both men and women with functional limitations, the main helper with their limitations is their spouse (47\%) while $24 \%$ was provided by paid carers.

- For older adults who receive help from paid carers through home support, 59\% was state-provided home support while the remainder was privately sourced.

- A small number of older adults with no functional limitations received state-funded home support. Most of these individuals have a long-term illness (81\%) or at least one chronic condition.

- Of those older adults with basic functional limitations who received no help, one in five $(18 \%)$ reported that they needed help all of the time but received none, while the majority felt they need help either some of the time (41\%), or none of the time (41\%).

- The majority (65\%) of participants who had received help with their functional limitations report that the help met their needs all of the time, while a further one in four (24\%) report that it usually meets their needs, while one in ten (10\%) reported that the help only sometimes or hardly ever meets their needs.

- The older population continue to contribute substantially to the informal care of their family and friends. Overall, in Wave $57 \%$ of women and $5 \%$ of men reported they had cared for someone in the past week equating to 68,500 people aged 58 and over. 
- In Wave 5, 28\% of carers report that the care was given to a spouse, $33 \%$ to another relative, and $10 \%$ to a friend or neighbour. For older carers aged 75 years and over, the main recipient was their spouse (38\%), while $17 \%$ care for another relative and $18 \%$ for a friend or neighbour. Carers aged 50-64 years are more likely to report the care recipient was another relative (49\% in Wave 5) and for $19 \%$ the care recipient was their spouse.

- Compared to non-carers, women providing low intensity caring (up to 50 hours per week) reported better self-rated health and wellbeing (higher quality of life score), lower depressive symptoms, and higher functional mobility. While there are positive benefits for physical health and wellbeing, there is a threshold, and women reporting more than 50 hours of caring in the last week report higher depressive symptoms, lower quality of life, more chronic pain, and lower functional mobility measured by Timed-Up-and-Go (TUG).

- Men who were carers had lower depressive symptoms. Men providing more than 50 hours of caring in the past week had increased hypertension.

- To enable family caring to continue, state-provided home support must also be available to facilitate and support carers to retain their work and leisure pursuits in addition to their care responsibilities. 


\section{Introduction}

The ultimate goal of healthy ageing, as defined by the World Report (2015), is sustaining wellbeing, through maintaining functional ability and enabling those with a lower physical and mental capacity to still do the things that are important to them (1). This can be achieved through maintaining physical function through preventative behaviours; it is also enabled through strong social networks and good access to health and social care (1). Populations are aging worldwide, and the estimated number of people aged over 60 years is projected to more than double, from 962 million in 2017 to 2.1 billion by 2050 (2). A combination of improvements in healthcare and lifestyles have contributed to this increased longevity (1). However, the changing demographic structure of the population will inevitably lead to a corresponding increase in the number of older people who are care dependent. Ireland provides formal, state-provided social care services on a means-tested basis, in addition to a number of other payments for those who provide care to family members including the two main social welfare payments Carer's Allowance and Carer's Benefit payment. Previous TILDA reports have documented the access to social and community care services by the older population in Ireland by frailty and disability status $(3,4)$. While community-based care can facilitate ageing in place, and has the potential to delay admission to a nursing home and improve quality of life (5), the majority of caring is likely to be provided as unpaid, informal care by a family member.

Family caring can impose considerable economic, social and emotional demands on the carer and may negatively affect their physical, emotional, and mental health. Previous research from Care Alliance Ireland found carers reported poor self-rated health, and worse health outcomes compared to non-carers (6). Informal caring has been found to be associated with increased stress, depression and ill health (7-9). A higher carer burden is associated with a more adverse health profile and poorer quality of life (8). Alternatively, research also shows there are a variety of positive gains from providing care and support for loved ones: it is associated with reward (10); a sense of purpose increased gratification; developing a closer relationship with the person receiving care (11); and involvement in productive and rewarding activities (12). Similarly, the impact of caring on risk of mortality differs: while some prospective studies document an increased risk of mortality among carers that rises with the amount of self-reported strain experienced (13), others have reported reduced risk of mortality among carers $(14,15)$. 
Previous research from the English Longitudinal Study on Ageing (ELSA) suggested that the quality of the activities in which people are encouraged to participate post-retirement, particularly the quality of the experience of caring, is important to their overall health outcomes (12).

In this report, firstly we estimate the proportion of the Irish population who report difficulty with at least one activity of daily living (ADL) or one instrumental activity of daily living (IADL) and receive help from family members, and we examine if this has changed over time between 2009 and 2018. We also examine what proportion of the population received state-funded home support or privately funded home support, determine if this has changed over time and estimate the prevalence of unmet need for the population who require help with IADL and ADL limitations. As discussed, caring can affect the health of a carer also, so in the second part of this report we characterise family carers and examine the health of the older population who report they have cared for someone in the past month. To do this we carry out a cross-wave analysis where we compare the cross-sectional distributions of receipt and giving of care between Wave 1 and Wave 5, and examine whether these vary with age, sex, educational attainment, marital status and wellbeing, health and physical function.

\subsection{Data and Methods}

This report uses data collected in the first five waves of The Irish Longitudinal Study on Ageing (TILDA), a prospective study of 8,174 community-dwelling adults aged 50 years and older in Ireland. Since 2009, TILDA has collected information about the heath, wealth and social circumstances of participants using a comprehensive Computer Assisted Personal Interview (CAPI) conducted by social interviewers who visited the participants in their own homes every 2 years (16). This included detailed questions on sociodemographics, living circumstances, income and wealth, physical, mental and behavioural health, health care utilisation and social participation. Participants were also asked to fill out a self-completion questionnaire (SCQ) which included more sensitive questions about relationships and experiences of growing older. The response rate for the SCQ was $84.5 \%$ $(n=6,914)$. For this report, cross-sectional analysis by wave is presented for participants in each wave; Wave $1=8,174$, Wave $2=7,281$, Wave $3=6,618$, Wave $4=5,942$ and Wave $5=5,206$. 


\subsection{Statistical methods and weighting}

In this report, the percentage of respondents classified into different groups or average scores (means) on the different outcome scales are presented. Most estimates are provided with a $95 \%$ confidence interval. This can be interpreted as a $95 \%$ chance that the sampled confidence interval includes the true population value. All estimates are weighted to account for age, sex, educational attainment and urban/rural residence in the 2011

Census, and to reflect the probability that participants returned a completed SCQ, ensuring that these estimates are representative of the whole population aged 50 years and over in Ireland.

\subsection{Structure of the Report}

The report is organised as follows. Chapter 1 provides a background to the topic, describing the current research on caring in the context of an ageing population. Chapter 2 describes the characteristics of the community-dwelling adults aged 50 years and over resident in Ireland; the prevalence of disability and use of family caring; state-funded home care services; and privately-funded home care, stratified by age group, sex, marital status, educational attainment and local area. It also examines unmet need for assistance with activities of daily living and instrumental activities of daily living. Chapter 3 describes older adults who are carers and describes to whom and how much family caring is provided. Chapter 4 explores the associations of caring with wellbeing, health and physical function. Finally, Chapter 5 summarises the findings, highlights their relevance to successful ageing and suggests areas in which these findings could inform policy and practice. 


\section{Prevalence of functional disability and receipt of care}

\subsection{Characteristics of sample}

Basic demographic indicators (age, sex, educational status) were obtained during the CAPI. Educational status was defined as primary, secondary or tertiary, corresponding to $\leq 8,9-13$ and $>13$ years of education respectively. Marital status (married, single, separated/divorced, widowed) and local area (Dublin city or county, another town/city, rural area) were also obtained.

Descriptive characteristics of the 8,174 participants aged 50 years and over who provided information in Wave 1 are shown in Table 1. Two thirds (64.5\%) were aged between 50 and 64 years, while one in six (12.3\%) were 75 years or over. $56.5 \%$ of the population aged 50 and over were women and the majority were married (68.3\%). Over one in four $(25.3 \%)$ lived in Dublin city or county while two-fifths lived in rural areas (44.2\%). It can be noted that as the TILDA cohort has aged, there are proportionately less in the 50-64 years age group, and more in the 65-74 and 75 years and over age groups. Similarly, the proportion married decreased slightly between Wave 1 and Wave 5, while the proportion who were widowed increased. 
Table 2.1. Descriptive characteristics of adults aged 50 years and over in Ireland (Wave 1Wave 5)

\begin{tabular}{|c|c|c|c|c|c|}
\hline & Wave 1 & Wave 2 & Wave 3 & Wave 4 & Wave 5 \\
\hline & $\begin{array}{c}8170 \\
\%(95 \% \mathrm{Cl})\end{array}$ & $\begin{array}{c}7119 \\
\%(95 \% \mathrm{Cl})\end{array}$ & $\begin{array}{c}6458 \\
\%(95 \% \mathrm{Cl})\end{array}$ & $\begin{array}{c}5801 \\
\%(95 \% \mathrm{Cl})\end{array}$ & $\begin{array}{c}5087 \\
\%(95 \% \mathrm{Cl})\end{array}$ \\
\hline \multicolumn{6}{|l|}{ Age } \\
\hline 50-64 years & $65(63-66)$ & $58(56-60)$ & $49(47-51)$ & $40(38-42)$ & $31(29-33)$ \\
\hline $65-74$ years & $23(22-25)$ & $28(27-30)$ & $33(32-35)$ & $37(36-39)$ & $39(37-40)$ \\
\hline$\geq 75$ years & $12(11-14)$ & $14(12-15)$ & $18(16-19)$ & $23(21-24)$ & $31(29-32)$ \\
\hline \multicolumn{6}{|l|}{ Education } \\
\hline Primary level & $28(26-30)$ & $28(26-30)$ & $28(26-30)$ & $28(26-29)$ & $27(26-29)$ \\
\hline Secondary level & $48(47-50)$ & $47(45-48)$ & $46(44-48)$ & $46(44-48)$ & $45(44-47)$ \\
\hline Tertiary level & $24(22-25)$ & $26(24-27)$ & $26(25-28)$ & $27(25-28)$ & 27 (26-29) \\
\hline \multicolumn{6}{|l|}{ Marital status } \\
\hline Married & $68(67-70)$ & $67(65-69)$ & $65(64-67)$ & $64(62-66)$ & $63(61-65)$ \\
\hline Single & $12(11-13)$ & $12(11-13)$ & $12(11-13)$ & $12(11-13)$ & $12(10-13)$ \\
\hline Separated/divorced & $9(8-10)$ & $9(8-10)$ & $9(8-10)$ & $9(8-10)$ & $8(7-9)$ \\
\hline Widowed & $11(10-12)$ & $12(11-14)$ & $14(13-15)$ & $15(14-17)$ & $17(16-19)$ \\
\hline
\end{tabular}

\subsection{Functional disability in the over 50s Wave 1 to Wave 5}

In TILDA, functional disability is measured as self-reported limitations in the activities of daily living (ADLs: help with walking across a room, dressing, bathing, eating, getting in and out of bed, and using the toilet) and instrumental activities of daily living (IADLs: preparing meals, shopping for groceries, making telephone calls, taking medications and managing money). Health professionals often use these activities as a measure of disability or functional status. The number of ADL limitations and IADL limitations was calculated and categorised as No limitations, IADL limitations only and any ADL limitation.

The number of IADL and ADL limitations reported between Wave 1 and Wave 5, by age group and gender, are shown in Figures 2.1 and 2.2. The proportion of participants reporting at least one $A D L$ increased to $11 \%$ of men and $12 \%$ of women in Wave 5 compared to $8 \%$ of men and $7 \%$ of women in Wave 1 . A similar increase is seen for IADL; $7 \%$ of men and $13 \%$ of women reported at least one IADL limitation in Wave 5, compared to $4 \%$ and $7 \%$ in Wave 1 respectively. The highest number of limitations are reported in men and women aged 75 and over, and these increased between Wave 1 and Wave 5 (Figure 2.1 and 2.2). 
Figure 2.1. Mean number of ADL limitations in Wave 1 to Wave 5, by age group and sex $0.5^{-}$Male

$0.4-$

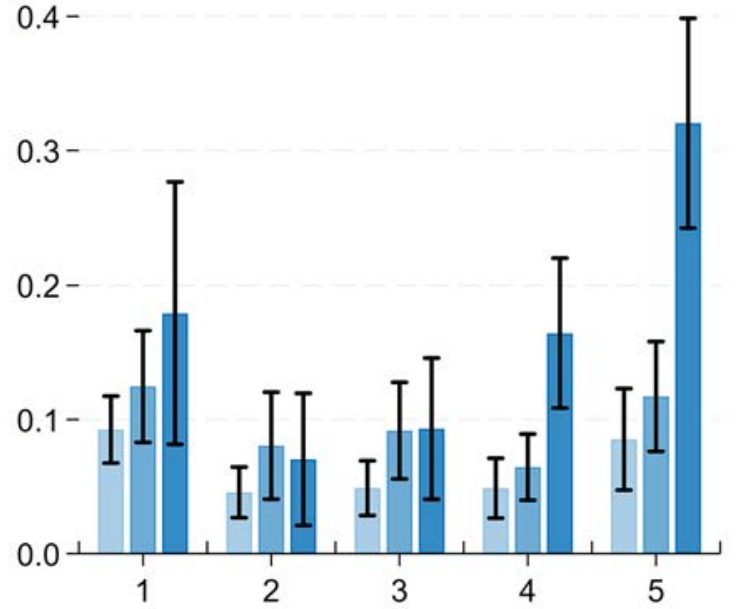

Female

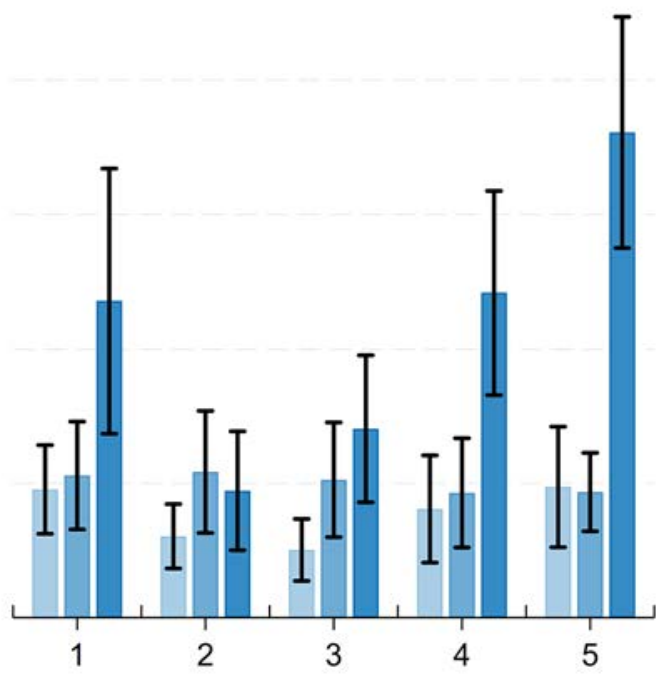

$50-64$

$65-74$ $>=75$

Figure 2.2. Mean number of IADL limitations in Wave 1 to Wave 5, by age group and sex

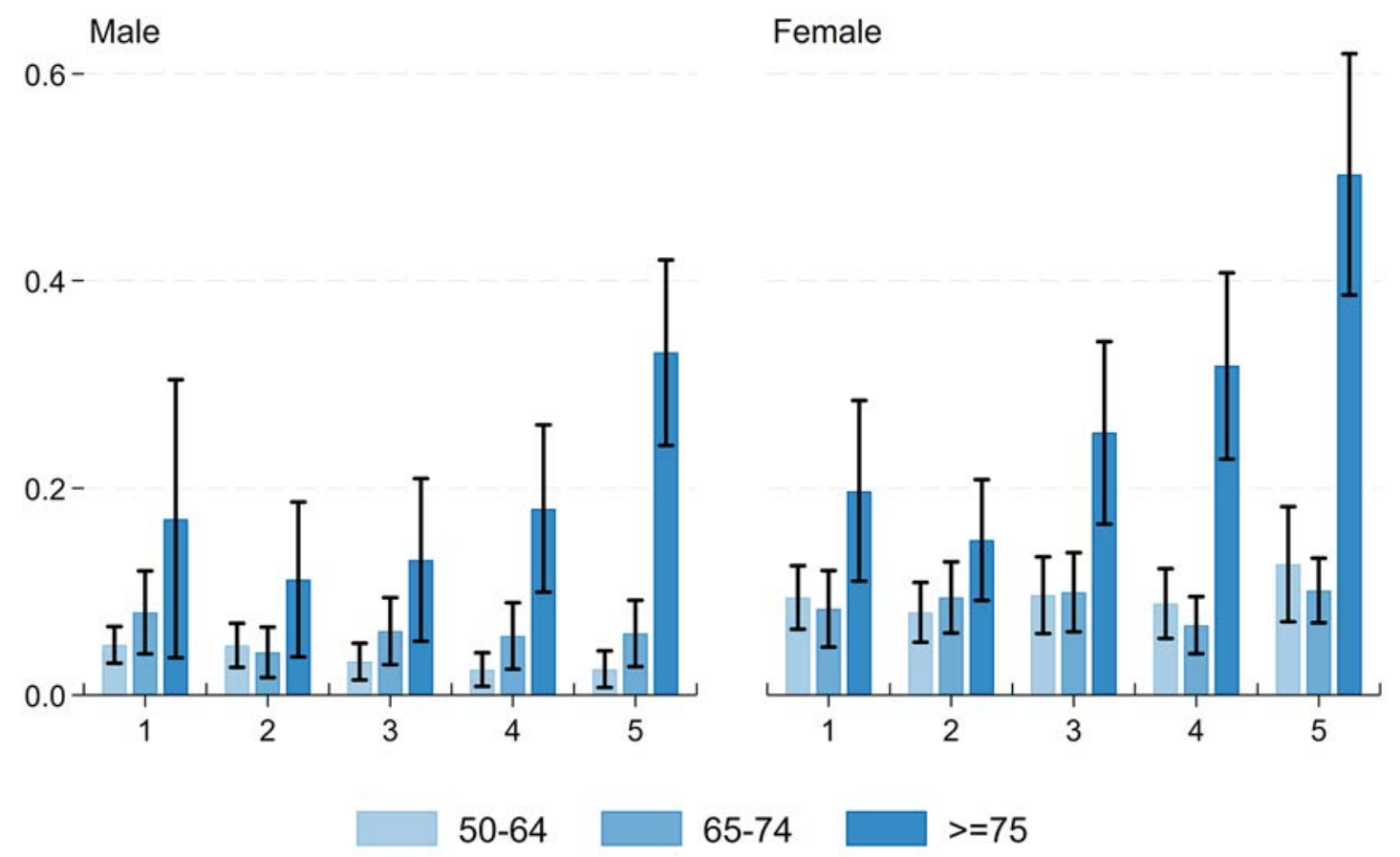

The proportion of the population who have some functional disability is shown in Table 2.2. 
The proportions are similar in men and women and increased between Wave 1 and Wave 5 from $10 \%$ to $15 \%$ respectively.

Table 2.2. Proportion of adults aged 50 years and over by functional disability status in Ireland, Wave 1 to Wave 5

\begin{tabular}{|c|c|c|c|c|c|c|c|c|}
\hline \multirow{2}{*}{ Study Wave } & \multicolumn{2}{|c|}{ Not disabled } & \multicolumn{2}{|c|}{$\begin{array}{c}\text { IADL } \\
\text { disability only }\end{array}$} & \multicolumn{2}{|c|}{$\begin{array}{l}\text { Any ADL } \\
\text { disability }\end{array}$} & \multirow{2}{*}{ Total } & \multirow{2}{*}{$\begin{array}{l}\text { Number in } \\
\text { Sample }\end{array}$} \\
\hline & $\%$ & $95 \% \mathrm{Cl}$ & $\%$ & $95 \% \mathrm{Cl}$ & $\%$ & $95 \% \mathrm{Cl}$ & & \\
\hline \multicolumn{9}{|l|}{ Male } \\
\hline 1 & 90 & [89-92] & 2 & {$[1-3]$} & 8 & [7-9] & 100 & 3744 \\
\hline 2 & 94 & [93-95] & 2 & [2-3] & 4 & [3-5] & 100 & 3219 \\
\hline 3 & 93 & [92-94] & 2 & [1-3] & 5 & {$[4-6]$} & 100 & 2863 \\
\hline 4 & 91 & [90-93] & 2 & {$[1-3]$} & 7 & [5-8] & 100 & 2555 \\
\hline 5 & 87 & [85-88] & 2 & {$[2-3]$} & 11 & [9-13] & 100 & 2216 \\
\hline \multicolumn{9}{|l|}{ Female } \\
\hline 1 & 90 & [88-91] & 3 & [3-4] & 7 & [6-8] & 100 & 4430 \\
\hline 2 & 90 & [88-91] & 5 & {$[4-6]$} & 5 & {$[4-7]$} & 100 & 3902 \\
\hline 3 & 89 & [88-91] & 4 & [3-5] & 6 & [5-7] & 100 & 3596 \\
\hline 4 & 87 & [85-89] & 4 & {$[4-6]$} & 8 & [7-10] & 100 & 3246 \\
\hline 5 & 83 & [81-85] & 4 & {$[4-6]$} & 12 & [11-14] & 100 & 2871 \\
\hline \multicolumn{9}{|l|}{ Total } \\
\hline 1 & 90 & [89-91] & 3 & {$[2-3]$} & 7 & [6-8] & 100 & 8174 \\
\hline 2 & 92 & [91-93] & 4 & {$[3-4]$} & 5 & {$[4-5]$} & 100 & 7121 \\
\hline 3 & 91 & [90-92] & 3 & [3-4] & 5 & [5-6] & 100 & 6459 \\
\hline 4 & 89 & [88-90] & 3 & [3-4] & 8 & [7-9] & 100 & 5801 \\
\hline 5 & 85 & [83-86] & 4 & [3-4] & 12 & [11-13] & 100 & 5087 \\
\hline
\end{tabular}

Note. $\mathrm{Cl}=$ confidence interval

\subsection{Receipt of help with functional limitations}

We ask participants who report that they have a difficulty with a specific activity (ADL or $I A D L)$ if they received any help from someone else with carrying out the activity, and who it was that helped them. The prevalence of receipt of help with functional limitations in men and women is shown in Figure 2.3. Overall, $45 \%$ reported receiving help with ADL and IADL limitations in Wave 1, and this increased to $60 \%$ in Wave 5. More women received help than men, and this increased between Wave 1 and Wave 5, from 53\% in Wave 1 to 
$72 \%$ in Wave 5 , while for men this proportion was $45 \%$ in Wave 5 , increased from $36 \%$ in Wave 1 . The proportion of women aged 75 years and older receiving help with ADL and IADL increased from $56 \%$ in Wave 1 to $78 \%$ in Wave 5.

Figure 2.3. Prevalence of receipt of any help with functional limitations (ADL or IADL) by age and sex, Wave 1 to Wave 5

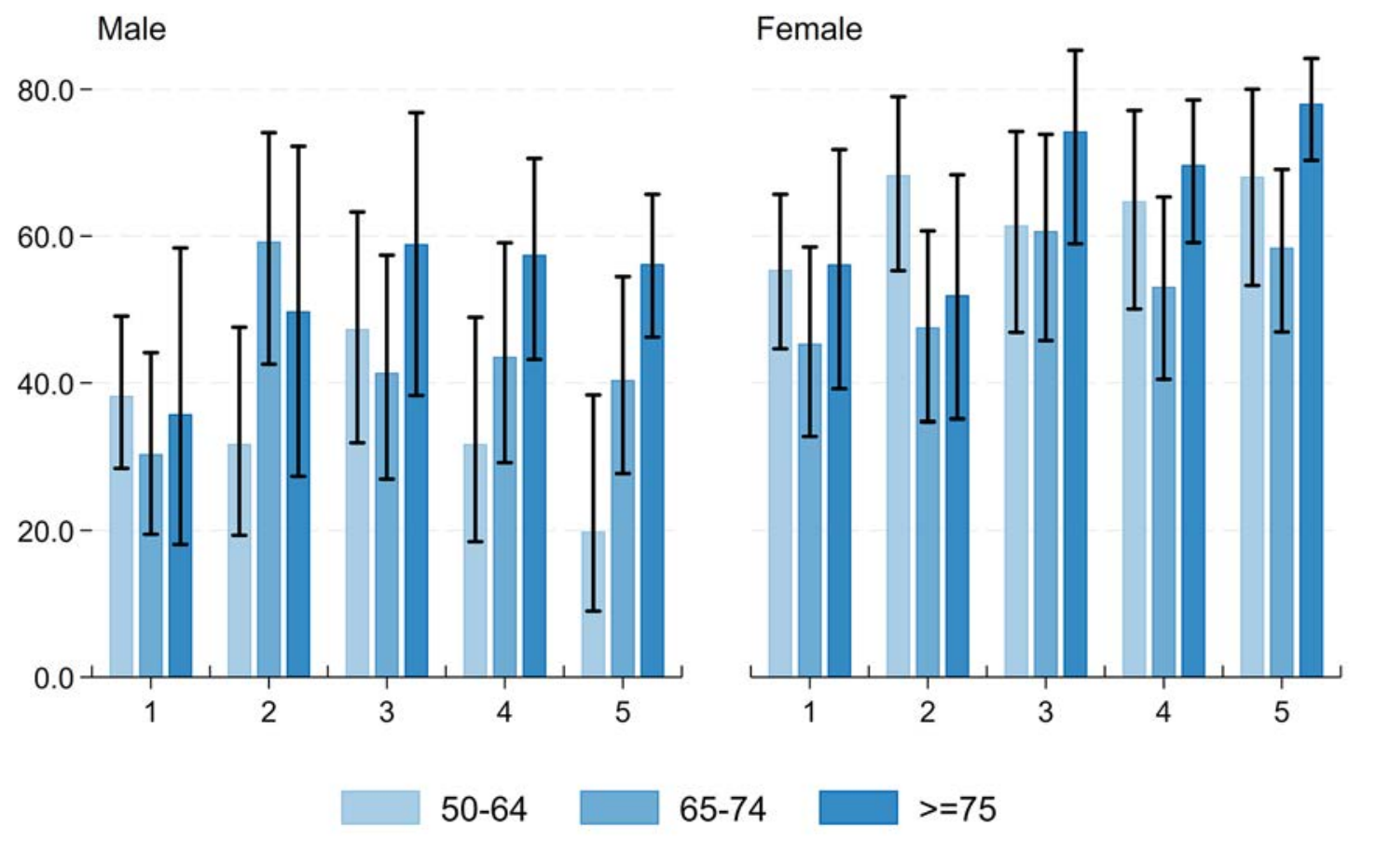

Receipt of help with ADL and IADL tasks varies by location (Figure 2.4). Older adults living in other towns or cities than Dublin and in rural areas report increases in receipt of help between Wave 1 and Wave 5, (from 41\% to $63 \%$ and 51\% to $67 \%$ respectively) while the proportion receiving help in Dublin city or county was lower and did not change (49\% in Wave 5). The increase was predominantly seen in women living in a rural area, where receipt of help increased from $45 \%$ to $76 \%$ in another town or city and from $61 \%$ to $78 \%$ in rural areas between Wave 1 and Wave 5. Receiving help also varies by educational attainment, with adults with primary education more likely to report receiving help with IADL or ADL limitations in Wave 5 (68\%, increased from 51\% in Wave 1), compared to those with tertiary education (44\% in Wave 5). For those who had primary education, the increases were predominantly seen in women; the proportion who received help increased from $60 \%$ to $83 \%$ for women between Wave 1 and Wave 5 (Figure 2.5). 
Figure 2.4. Prevalence of receipt of any help with functional limitations (ADL or IADL) by local area, sex, Wave 1 to Wave 5

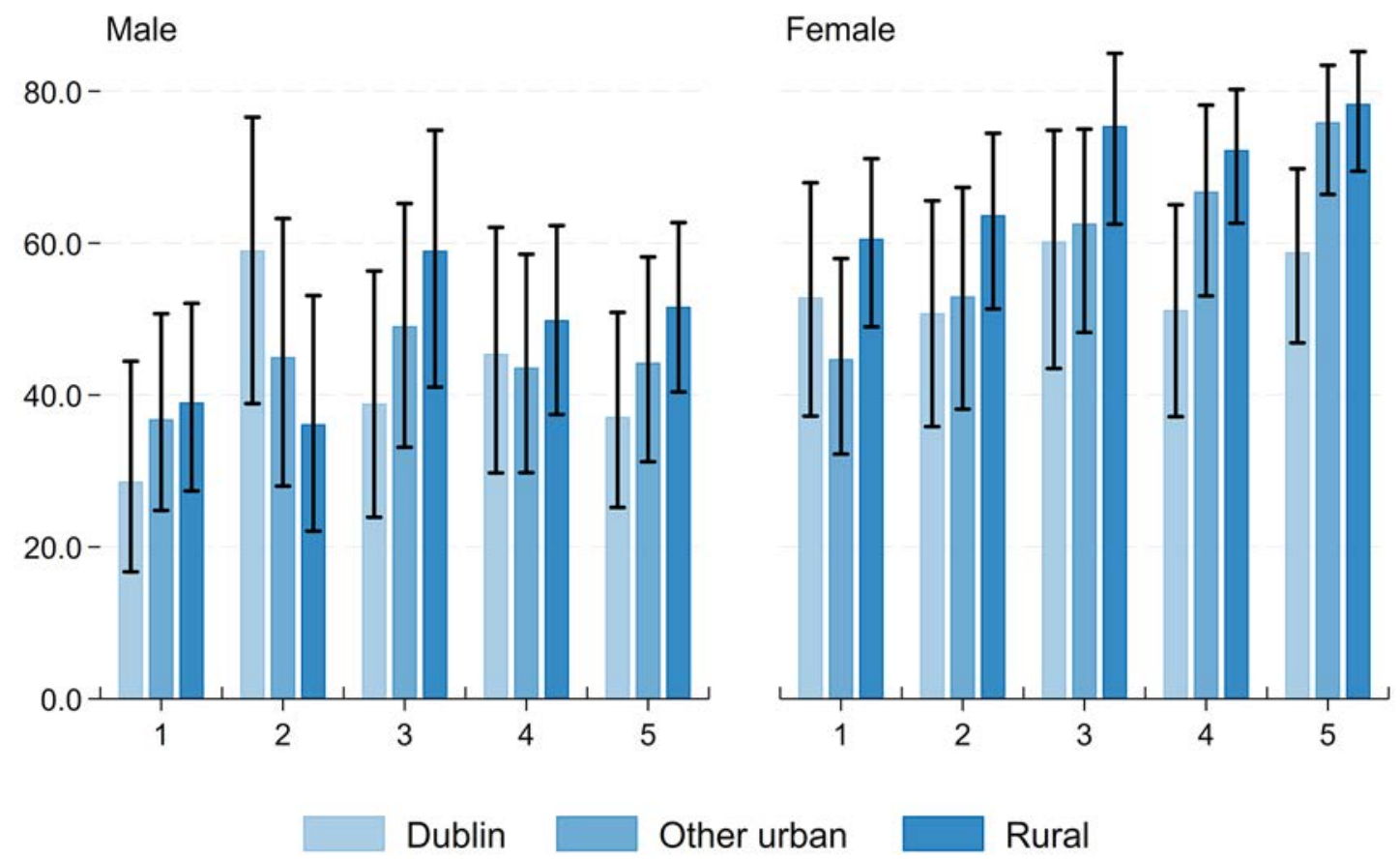

Figure 2.5. Prevalence of receipt of any help with functional limitations ( $A D L$ or IADL) by educational attainment, sex, Wave 1 to Wave 5

$100.0^{-}$Male

$80.0-$

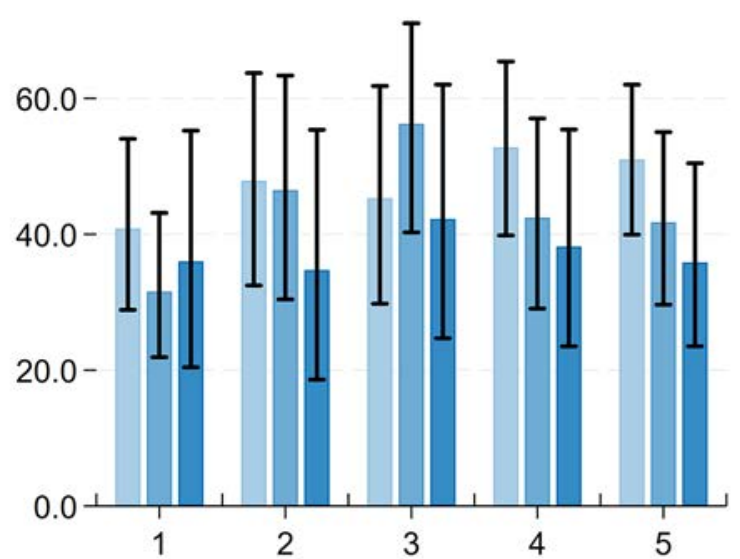

Female

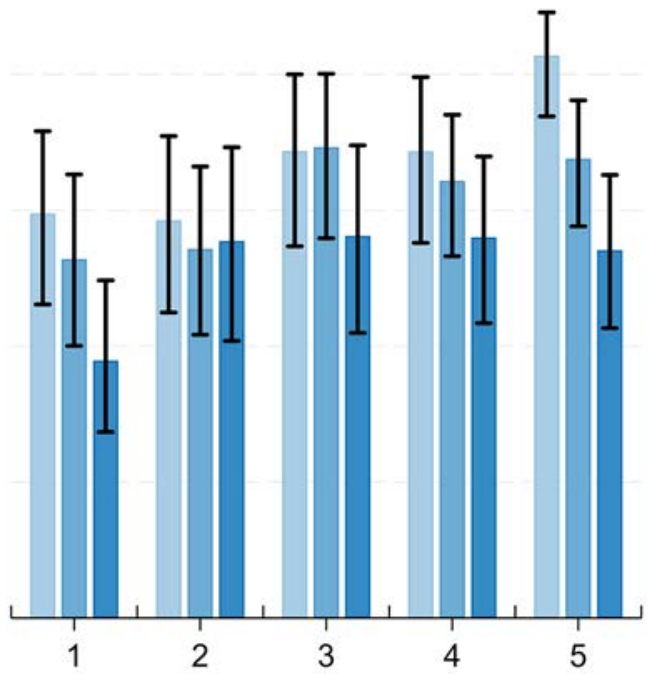

Primary/none

Secondary

Third/higher 


\subsection{Family and non-family carers}

Most help with ADL and IADL limitations is provided by family carers, although the proportion of help with ADLs provided by a non-relative increased between Wave 1 and Wave 5 for both men and women. Overall, $52 \%$ of help with ADL limitations in Wave 5 was provided by a non-relative, compared to $4 \%$ in Wave 2 . The majority of this care was provided by a paid carer (40\%) while $12 \%$ of care was provided by a non-relative who was not employed to be a carer (probably a neighbour or friend). Figure 2.6 shows that for those adults who report receiving help with ADL limitations, the main helper for men is their spouse in Wave $1(93 \%)$ but this reduced to $36 \%$ in Wave 5 . The proportion of help received from a non-relative increased from $9 \%$ to $61 \%$ in Wave 5 (42\% from paid carers and $19 \%$ from unpaid non-relative carers). The proportion provided by a child was $3 \%$ in Wave 1 and 1\% in Wave 5. For women, 60\% of help with ADL limitations was provided by a spouse in Wave 1 and this declined to $29 \%$ in Wave 5 . The proportion provided by a child decreased from $31 \%$ to $21 \%$ respectively, while $3 \%$ was provided by another relative other than a child or spouse. The proportion of help provided by a non-relative also increased for women to $48 \%$ in Wave $5,40 \%$ provided by a paid carer, and $8 \%$ from an unpaid non-relative (probably a friend or neighbour).

Figure 2.6. Proportion who are receiving help with ADL limitations by helper Wave 1 to Wave 5

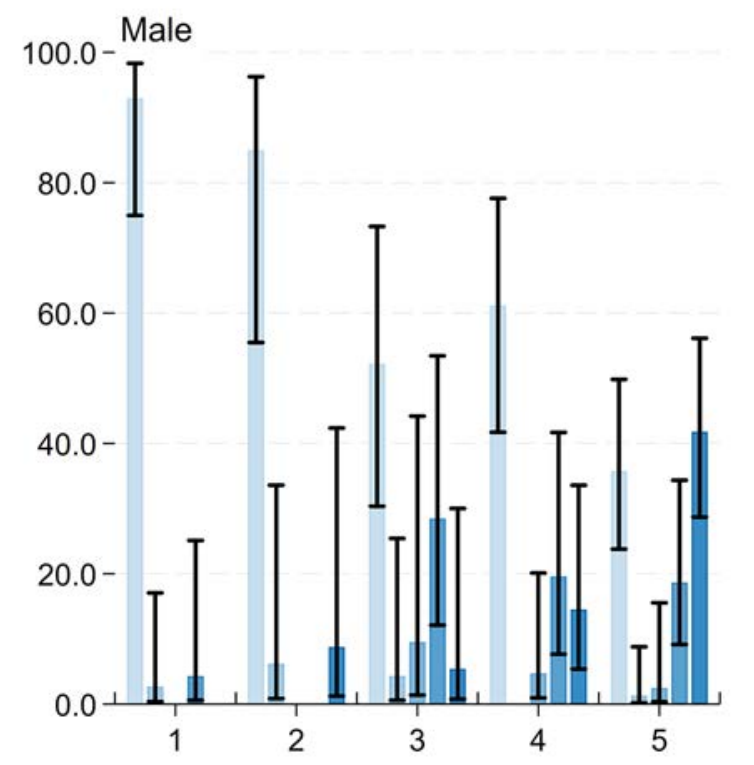

Spouse Child Other relative

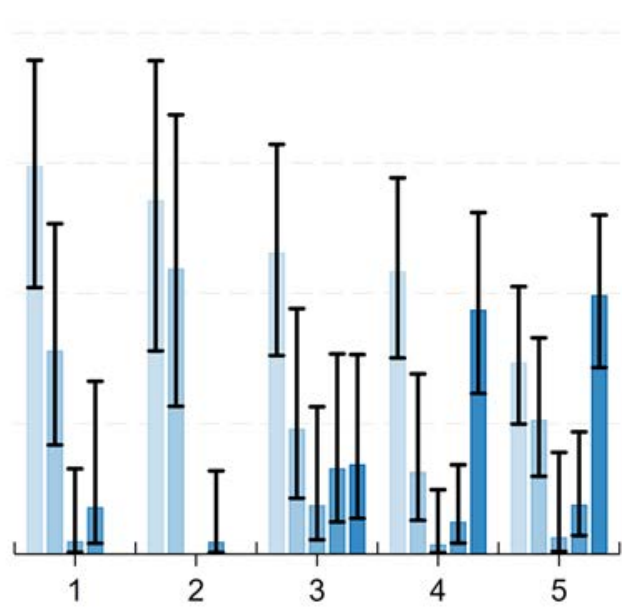

Non-relative Paid non-relative

Help with IADL limitations is predominantly provided by family carers for both men and 
women. For men, the main helper is their spouse, although this proportion decreased from $73 \%$ in Wave 1 to $46 \%$ in Wave 5 . In Wave 5, 16\% of IADL help is provided by children (increased from $6 \%$ in Wave 1 ) and $8 \%$ by other relatives, while $8 \%$ of help with IADL limitations for men is provided by non-relatives and $23 \%$ by paid carers. The proportion of help with IADL limitations provided by family carers varies for women, and their spouse remains the main helper with IADLs between Wave 1 and Wave 5 (49\%). There was a decrease in the proportion being provided with help by their children between Wave 1 and Wave 5 from $34 \%$ to $22 \%$, and a similar proportion of help from other relatives, $5 \%$ in Wave 1 and 5\% in Wave 5. Other relatives, in this context were a combination of grandchildren, in-laws and siblings. The proportion of help with IADL limitations provided by non-relatives increased to $25 \%$ in Wave $5 ; 2 \%$ is provided by non-relatives probably neighbours and friends and $22 \%$ is provided by paid carers.

Figure 2.7. Proportion who are receiving help with IADL limitations by helper Wave 1 to Wave 5

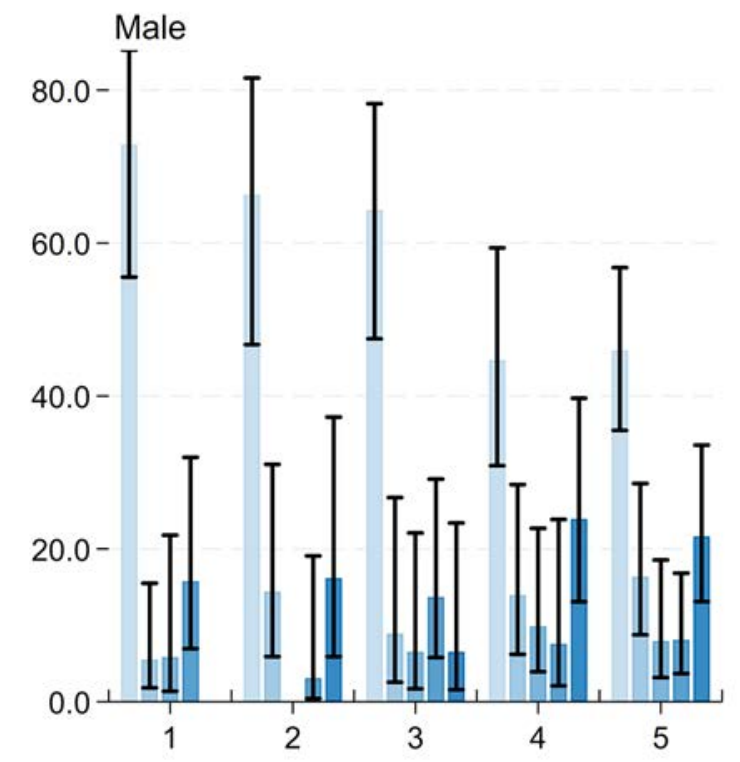

Female
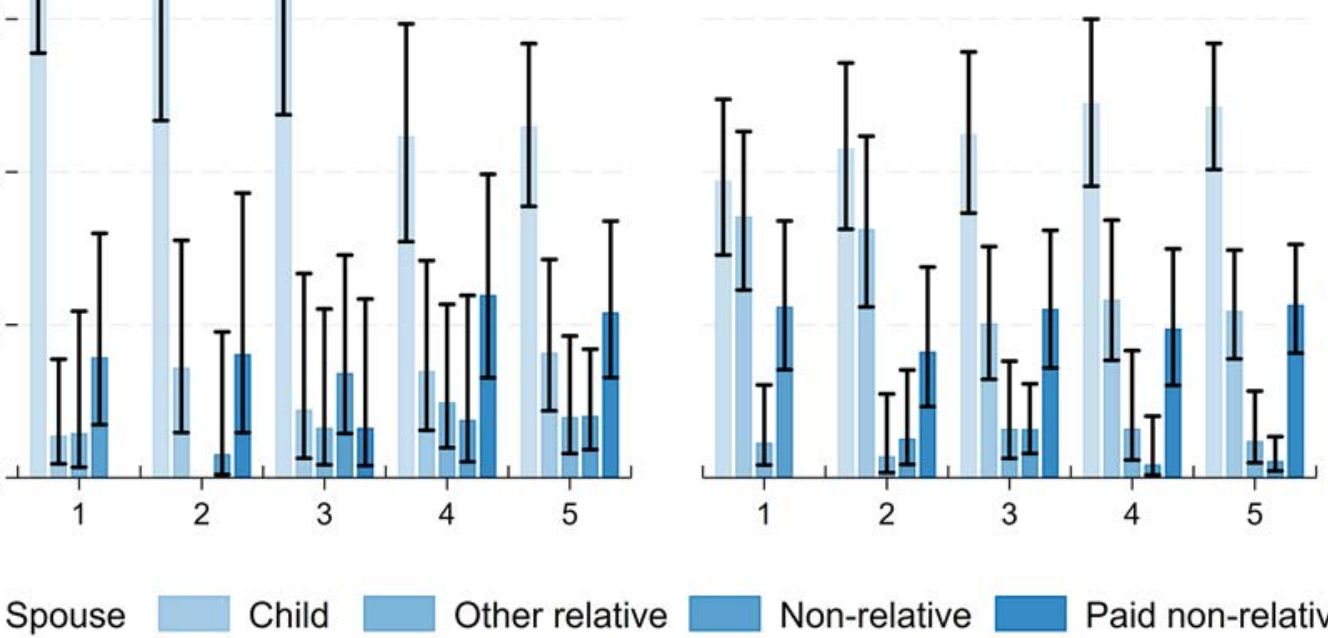

Spouse Child Other relative Non-relative Paid non-relative 


\subsection{Receipt of state and private-provided home support by disability status}

We also ask participants if they receive any state-provided home help (a person employed by the State to help with household chores such as cleaning and cooking) and personal care (a person employed by the State to assist with bathing, showering, bodily care etc.). In Wave 4 and Wave 5 we also asked participants if they had paid any individual or private company to provide home help or personal care. We combine both these types of help together and call it home support. Some of the non-relative care discussed above in section 2.4 will be acquired through this home help service.

Figure 2.8. The proportion of participants receiving state-provided home support in Wave 1 to Wave 5, by age and sex

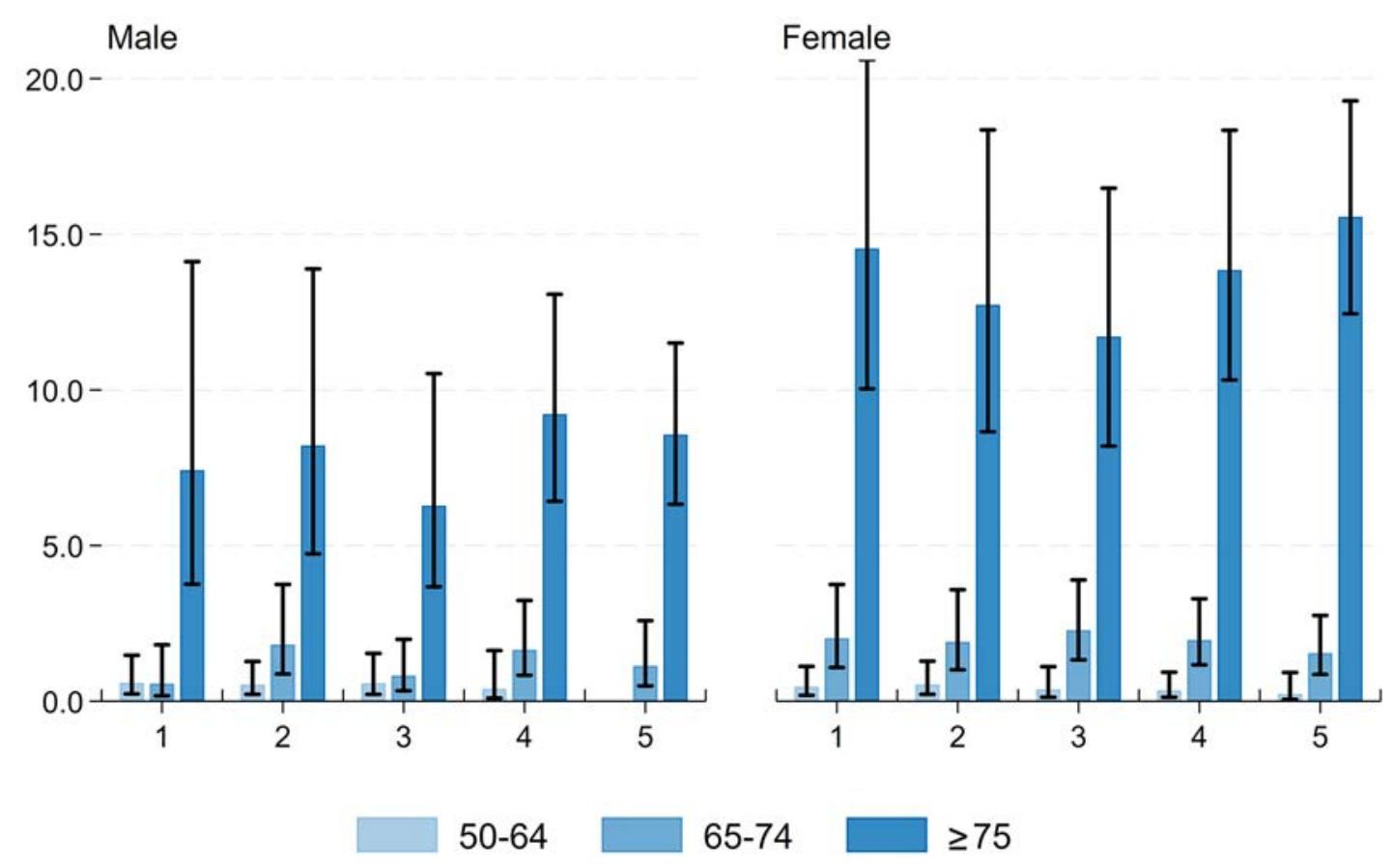


Figure 2.9. The proportion of participants receiving private paid home support in Wave 4 to Wave 5, by age and sex

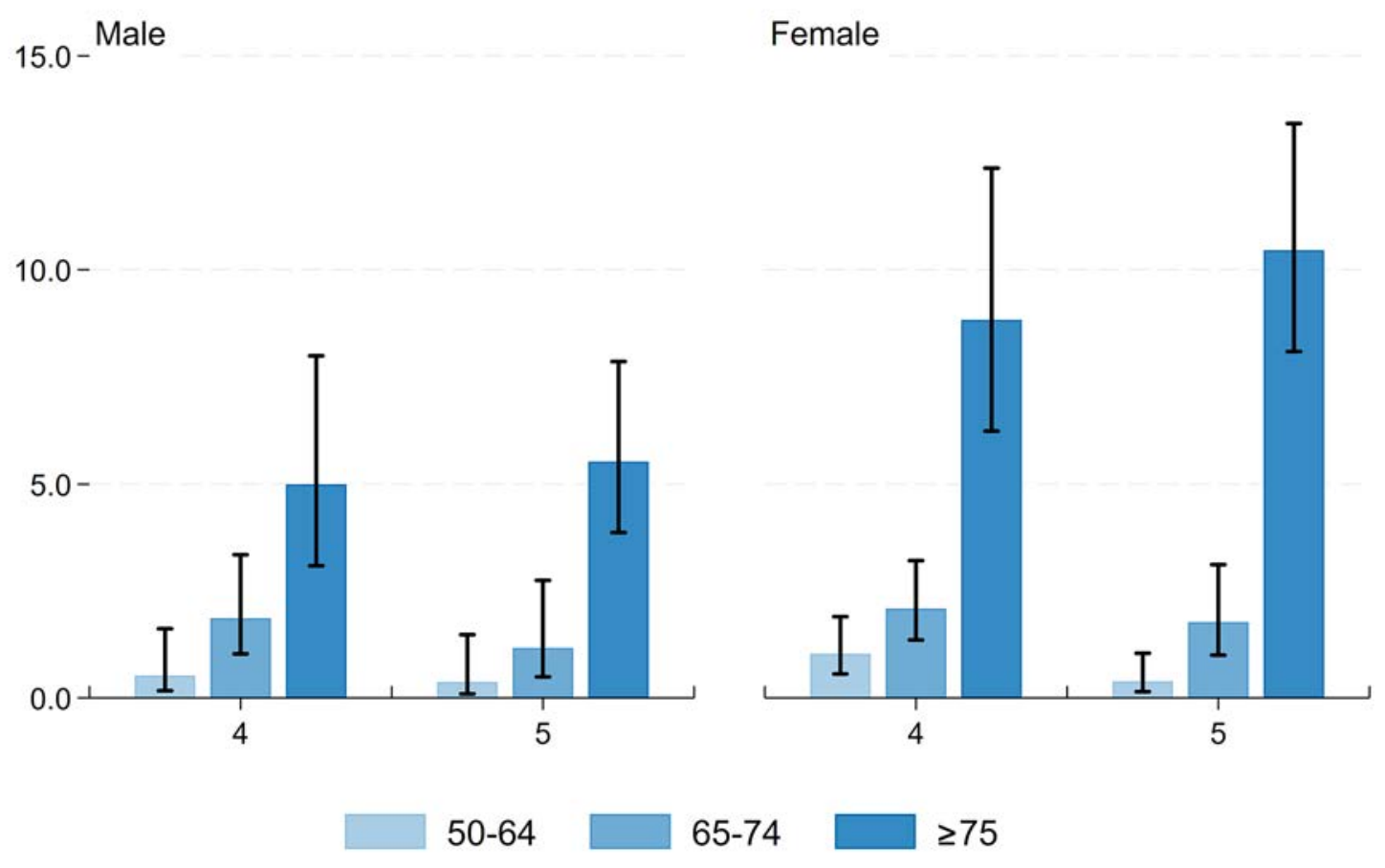

Overall, in Wave 5 4.9\% received state-provided home support, an increase from $2.1 \%$ in Wave 1 (Figure 2.8). The proportion receiving home support varies by age. 14\% of adults aged 75 years and over report receiving state-provided home support in Wave 5 , and this was consistent between Wave 1 and Wave 5. Figure 2.9 shows that a further $3.2 \%$ received private home support in Wave 5 , and that the proportion of women receiving private home support was higher than men (10\% and 12\% versus 5\%, in Wave 4 and Wave 5 respectively).

Table 2.3 shows the proportion of older adults receiving any help with functional disability, combining both family caring and state and private home support, and that this increased between Wave 1 and Wave 5. Altogether, 7.6\% received some form of home support, either state-provided or privately sourced, in Wave 5 . The proportion receiving home support varies by functional disability status. A small number of participants with no IADL or ADL limitations received state home support. The majority of these individuals have a longterm illness (81\%) or at least one chronic condition. For those adults with IADL limitations only, the proportion who received any help (including both family caring and home support) increased from $58.7 \%$ in Wave 1 , to $78.3 \%$ in Wave 5 , and the majority of that help was provided by family carers, with $29.7 \%$ receiving either state-provided or private home support in Wave 5. For older adults living with IADL limitations only, who receive home support, 59\% was state-provided home support while the remainder was privately sourced. 
There has also been an increase in help received for adults with any ADL limitations between Wave 1 and Wave 5, from 39.7\% to 52.7\%. A third (34.1\%) report they received any home support in Wave 5, of which three quarters was state-provided (25.1\% overall). This increased from $8.2 \%$ of adults reporting any ADL limitations receiving state-provided home support in Wave 1, when proportionately more of the help received was provided by family carers (Table 2.3). 
Table 2.3. Receipt of state and private provided home support and informal care by functional disability status

\begin{tabular}{|c|c|c|c|c|c|c|c|c|c|}
\hline & \multicolumn{2}{|c|}{$\begin{array}{l}\text { State home } \\
\text { support }\end{array}$} & \multicolumn{2}{|c|}{$\begin{array}{c}\text { Private home } \\
\text { support }\end{array}$} & \multicolumn{2}{|c|}{$\begin{array}{l}\text { Any home } \\
\text { support }\end{array}$} & \multicolumn{2}{|c|}{$\begin{array}{l}\text { Any help with } \\
\text { ADL or IADL } \\
\text { limitations }\end{array}$} & \multirow{2}{*}{$\begin{array}{l}\text { Number } \\
\text { in } \\
\text { Sample }\end{array}$} \\
\hline & $\%$ & $95 \% \mathrm{Cl}$ & $\%$ & $95 \% \mathrm{Cl}$ & $\%$ & $95 \% \mathrm{Cl}$ & $\%$ & $95 \% \mathrm{Cl}$ & \\
\hline \multicolumn{10}{|c|}{ Not disabled } \\
\hline 1 & 1.3 & $(0.9-1.9)$ & & & & & 0.0 & $(.-)$. & 7188 \\
\hline 2 & 1.4 & $(1.0-2.0)$ & & & & & 0.0 & $(.-)$. & 6507 \\
\hline 3 & 1.5 & $(1.1-2.1)$ & & & & & 0.0 & $(.-)$. & 5937 \\
\hline 4 & 1.8 & $(1.4-2.4)$ & 2.1 & $(1.6-2.7)$ & 3.6 & $(3.0-4.4)$ & 0.0 & $(.-)$. & 5258 \\
\hline 5 & 1.8 & $(1.3-2.4)$ & 2.0 & $(1.5-2.56)$ & 3.6 & $(2.9-4.4)$ & 0.0 & $(.-)$. & 4520 \\
\hline \multicolumn{10}{|c|}{ IADL disability only } \\
\hline 1 & 13.2 & $(6.8-24.1)$ & & & & & 58.7 & $(48.4-68.3)$ & 287 \\
\hline 2 & 17.1 & $(10.3-27.0)$ & & & & & 67.4 & $(57.2-76.5)$ & 311 \\
\hline 3 & 14.2 & (8.1-23.8) & & & & & 71.0 & $(60.5-79.6)$ & 238 \\
\hline 4 & 21.6 & $(13.3-33.1)$ & 7.2 & $(3.4-14.5)$ & 26.1 & $(17.1-37.8)$ & 68.3 & $(57.5-77.4)$ & 188 \\
\hline 5 & 17.8 & $(11.5-26.6)$ & 11.6 & $(6.5-19.8)$ & 29.0 & (20.8-38.9) & 84.5 & (76.2-90.3) & 162 \\
\hline
\end{tabular}

\section{Any ADL disability}

\begin{tabular}{|c|c|c|c|c|c|c|c|c|c|}
\hline 1 & 7.3 & $(4.4-12.8)$ & & & & & 40.0 & $(33.4-50.0)$ & 699 \\
\hline 2 & 11.0 & (6.6-17.6) & & & & & 40.7 & $(32.4-49.5)$ & 463 \\
\hline 3 & 13.9 & (8.8-21.1) & & & & & 53.8 & $(45.8-61.7)$ & 443 \\
\hline 4 & 17.8 & $(12.9-24.1)$ & 9.8 & $(6.7-14.2)$ & 24.2 & $(18.7 .4-30.6)$ & 52.0 & $(44.8-59.1)$ & 485 \\
\hline 5 & 21.8 & $(17.3-27.0)$ & 10.5 & $(7.5-14.5)$ & 29.2 & $(24.2-34.7)$ & 52.0 & $(46.2-57.8)$ & 520 \\
\hline \multicolumn{10}{|c|}{ Total } \\
\hline 1 & 2.1 & $(1.6-2.7)$ & & & & & 4.5 & $(3.8-5.3)$ & 8174 \\
\hline 2 & 2.4 & $(1.8-3.0)$ & & & & & 3.9 & $(3.2-4.6)$ & 7121 \\
\hline 3 & 2.5 & $(1.9-3.1)$ & & & & & 4.9 & $(41.2-5.7)$ & 6459 \\
\hline 4 & 3.4 & $(2.83-4.3)$ & 2.7 & $(2.2-3.3)$ & 5.7 & $(4.9-6.6)$ & 5.6 & $(4.8-6.4)$ & 5801 \\
\hline 5 & 4.3 & $(3.6-5.2)$ & 3.2 & $(2.6-3.9)$ & 7.0 & $(6.1-8.1)$ & 8.2 & $(7.2-9.3)$ & 5087 \\
\hline
\end{tabular}

Note: Home support includs home help and personal care attendant 


\subsection{Unmet need for help with ADLS and IADLS Wave 5}

In Wave 5, we asked participants who had not received any help with ADL limitations whether they would say that they needed help with any of those activities. Of the proportion who received no help, $67 \%$ stated they did not require help, $25 \%$ stated they need help some of the time and $5 \%$ reported that they needed help all of the time but received none (Figure 2.10).

Figure 2.10. $A D L$ limitations and unmet need in receiving help

$$
\text { All of the time } \square \text { Most of the time } \square \text { Some of the time } \square \text { None of the time }
$$

60.0

40.0

20.0

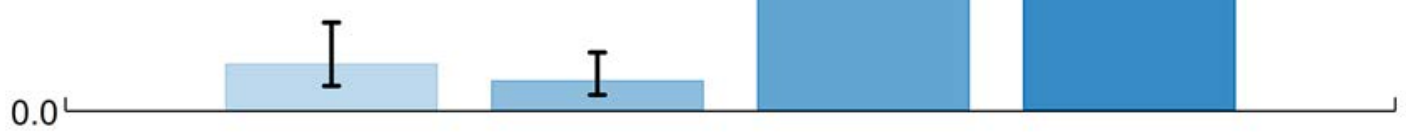

We asked a similar question for those adults with an IADL limitation who had not received any help. One third (34\%) who had received no help with their IADL limitation answered they did not need help; there was still some reported unmet need, with $8 \%$ reporting that they needed help all of the time, a further $8 \%$ most of the time and $51 \%$ some of the time (Figure 2.11).

When asked in Wave 5, 66\% of participants who received help with their ADLS and IADLs report that the help met their needs all of the time, while a further $24 \%$ report that it usually meets their needs, while $7 \%$ and $3 \%$ respectively reported that the help only sometimes or hardly ever meets their needs (Figure 2.12). 
Figure 2.11. Unmet need in those with IADL who have not received help

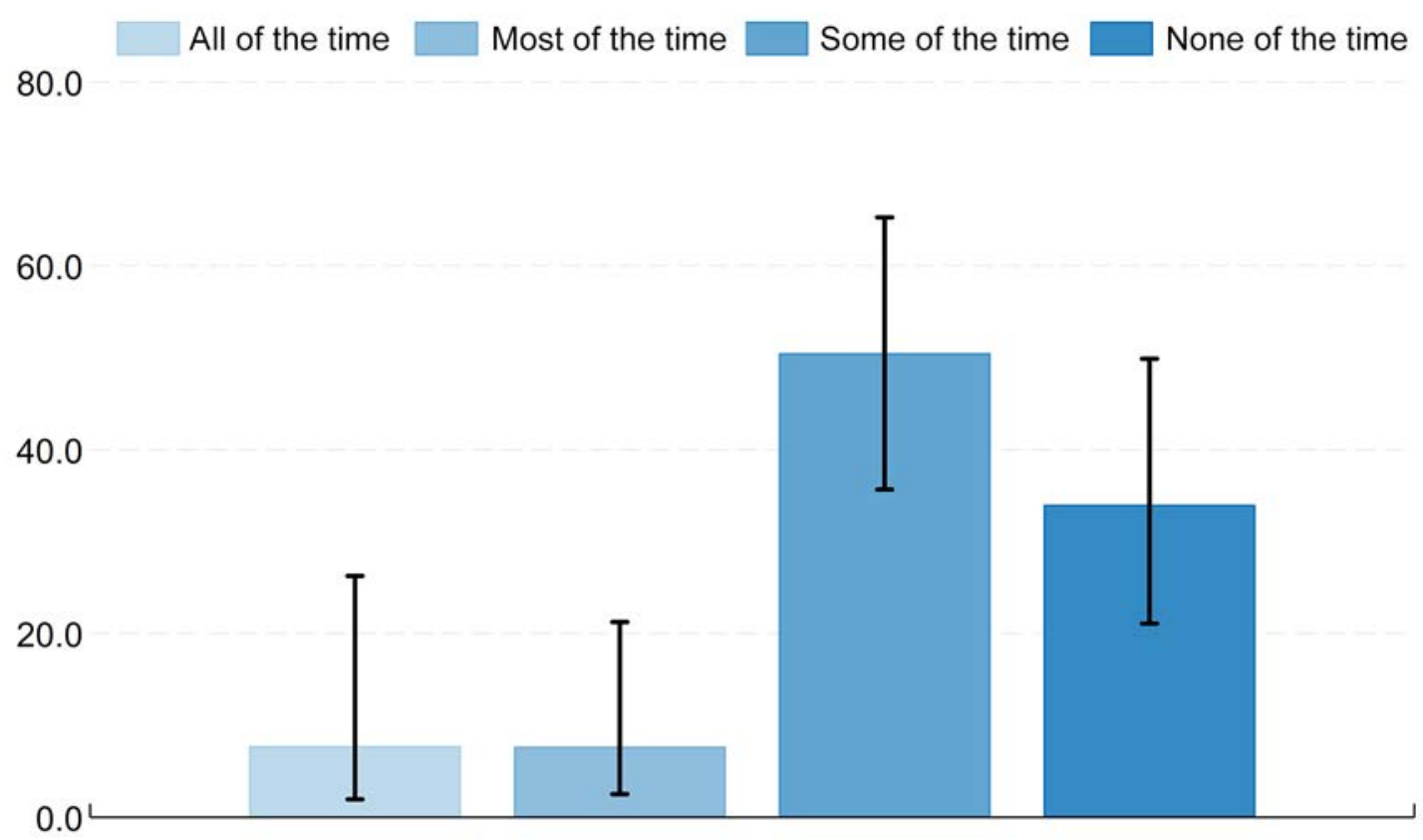

Figure 2.12. For those who received help with ADL or IADL limitations: was the help received enough to meet needs? (Wave 5)

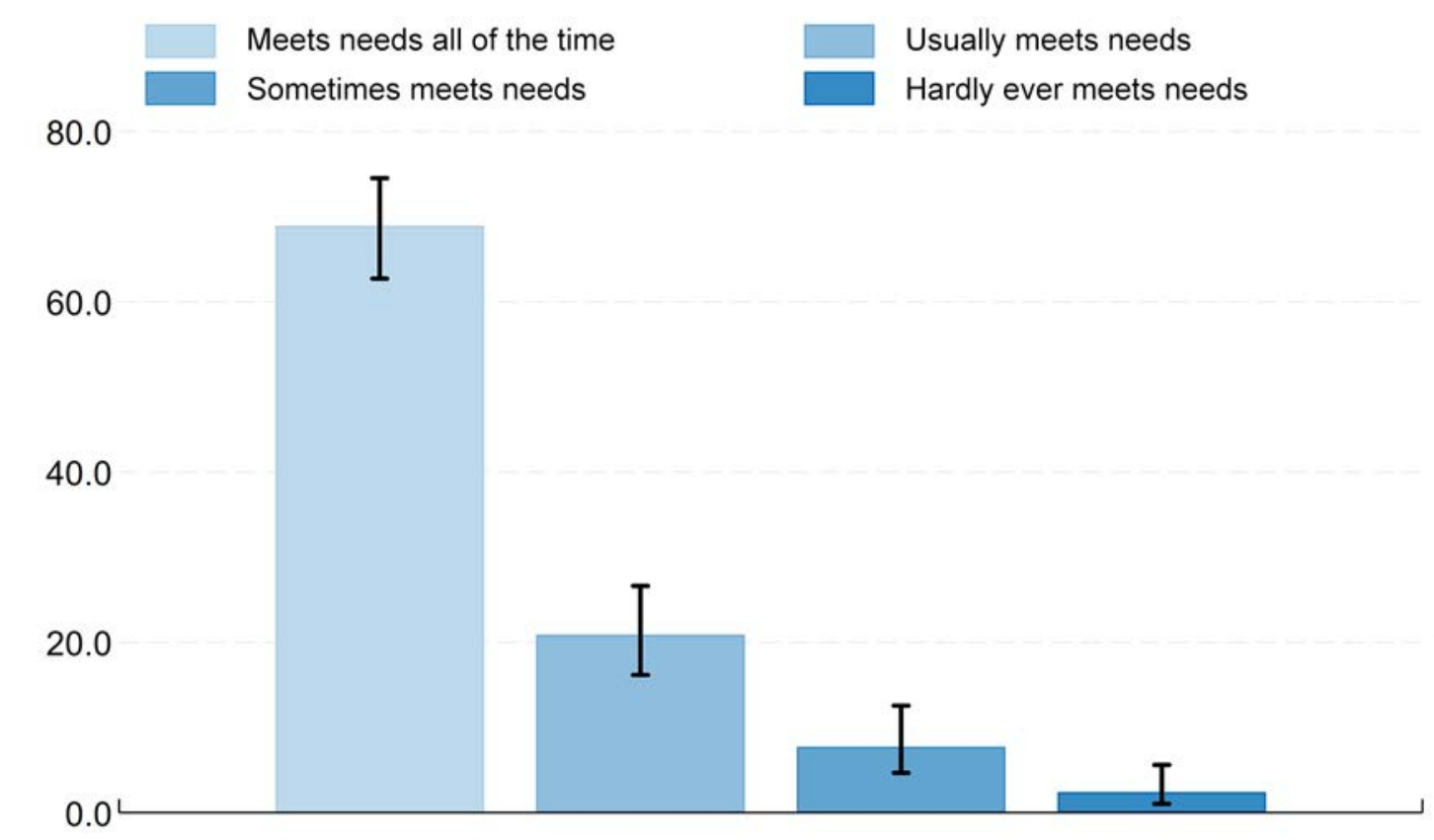




\section{Prevalence of caring in the older population in Ireland}

\subsection{Caring by demographic characteristics}

Participants were asked 'did you care for someone in the last month / in the last week?', and the numbers of hours spent doing so in the past week was recorded.

Women are more likely to report they cared for someone in the last month than men; this proportion declined between Wave 3 and Wave 5 from 10\% to 7\%, compared to $7 \%$ to $5 \%$ of men in Wave 5 (Figure 3.1). There are also differences between younger and older women (Figure 3.2). Women aged 50-64 and 65-74 years are more likely to report caring ( $9 \%$ and $8 \%$ respectively in Wave 5) compared to those aged 75 years and over (4\%). This age effect is not seen in men.

Figure 3.1. Prevalence of caring by sex, Wave 3 to Wave 5

$15.0^{-}$Male

$10.0-$

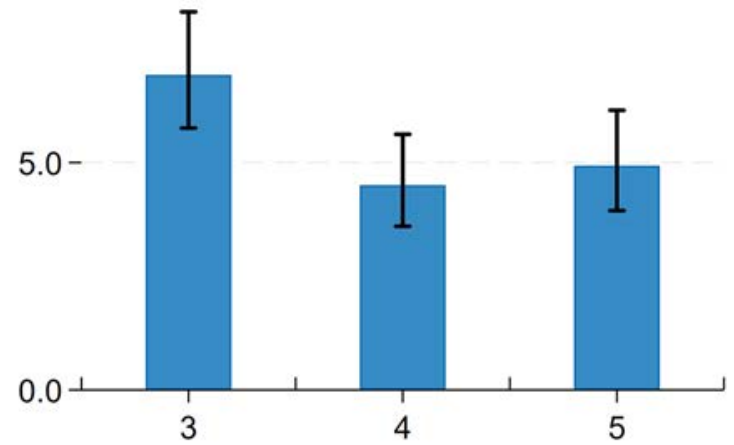

Provided care in the last month
Female

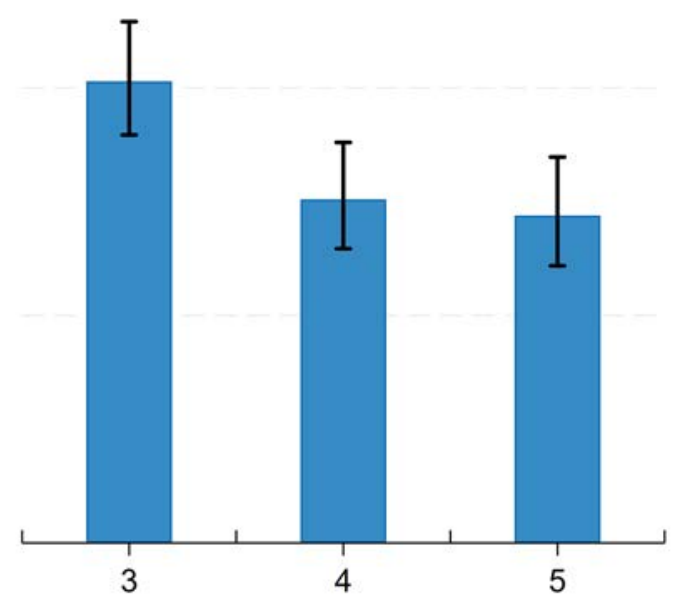

$\longmapsto 95 \%$ Confidence Interval 
Figure 3.2. Prevalence of caring by age group and sex, Wave 3 to Wave 5

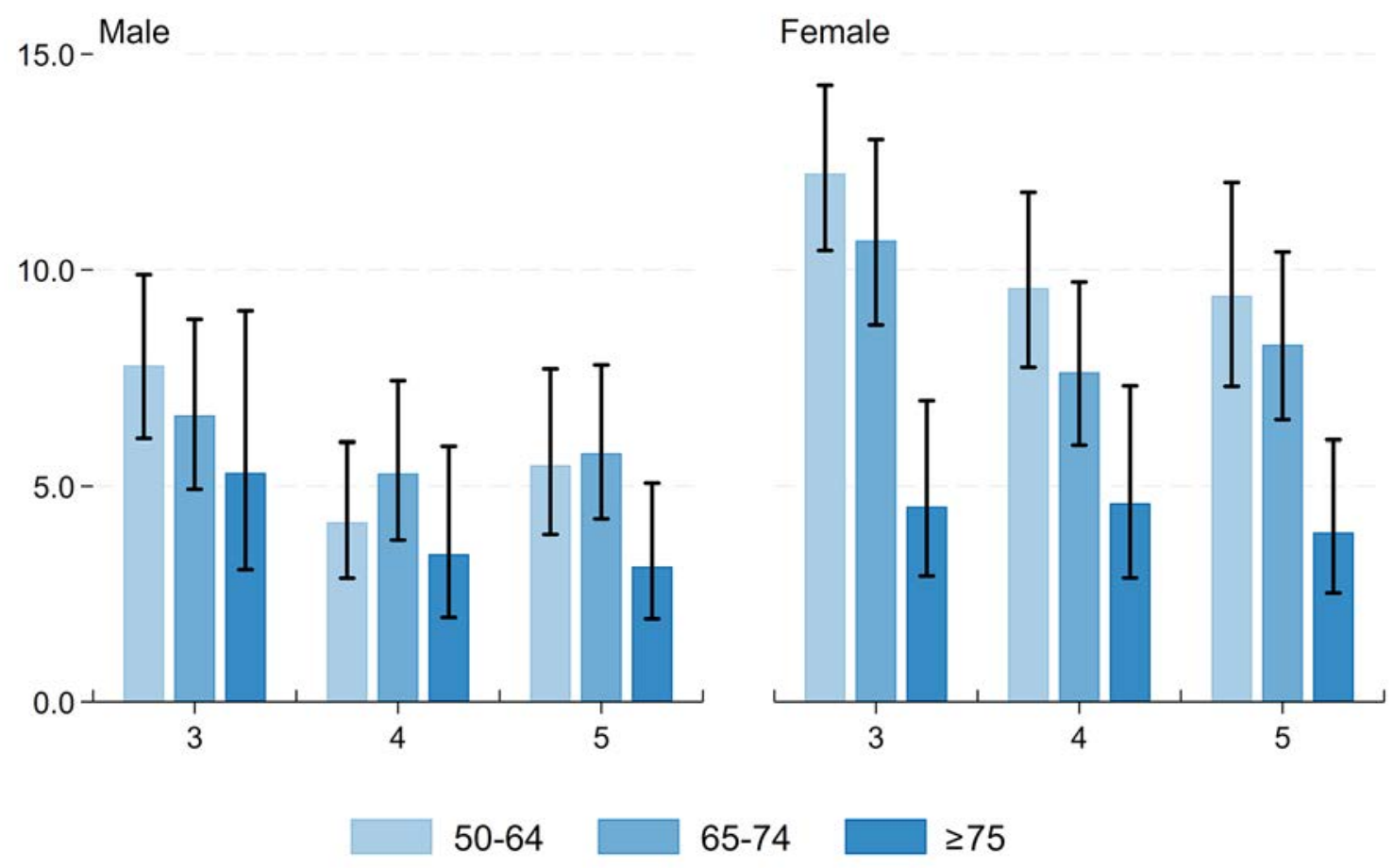

Caring varies with marital status, with married individuals more likely to report caring compared to those who are widowed (Figure 3.3).

Figure 3.3. Prevalence of caring by marital status and sex, Wave 3 to Wave 5

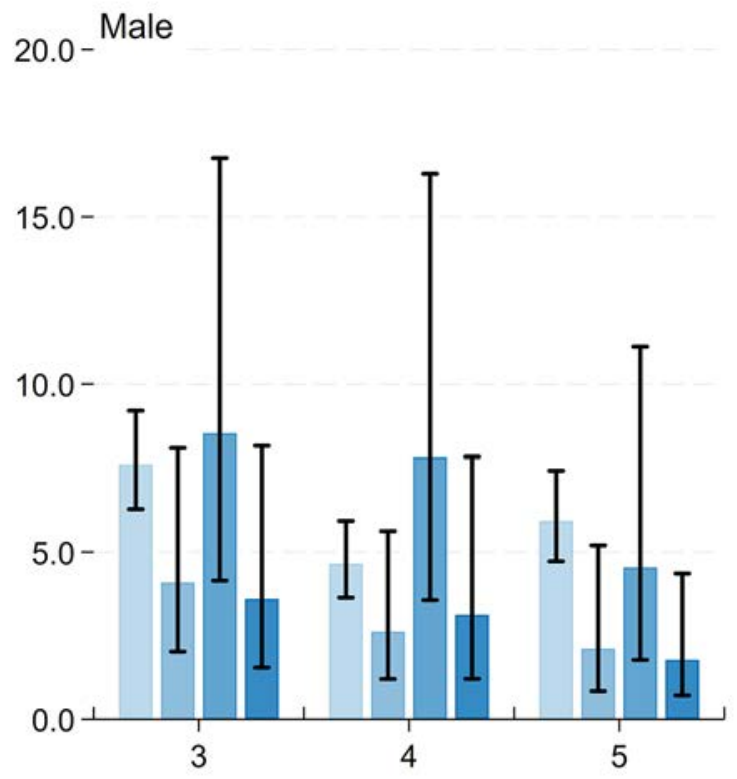

Female

\section{Married}

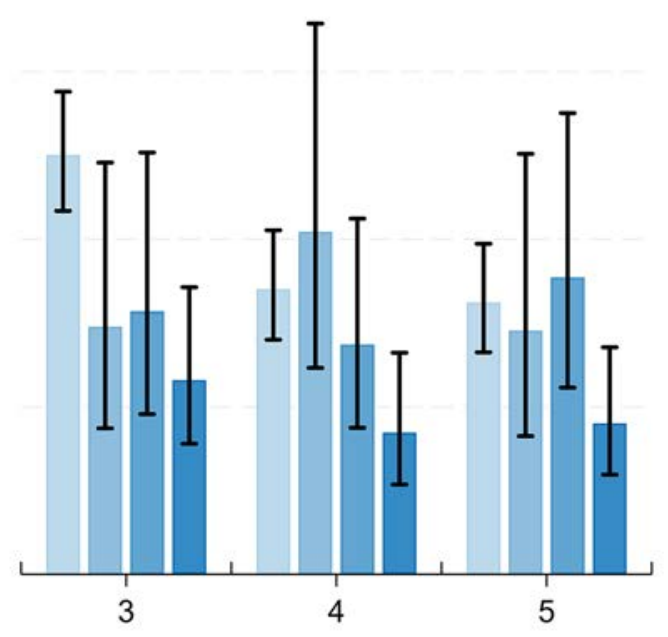

Sep/divorced

Widowed 
The proportion of older adults reporting caring decreased overall in those living in rural areas from $9 \%$ in Wave 3 to $5 \%$ in Wave 5, while the proportion reporting caring remained the same in Dublin and in other towns or cities (Figure 3.4). For men living in a rural area, this proportion decreased from $6 \%$ to $4 \%$, while for women it decreased from $12 \%$ to $7 \%$ between Wave 3 and Wave 5.

Figure 3.4. Prevalence of caring by local area and sex, Wave 3 to Wave 5

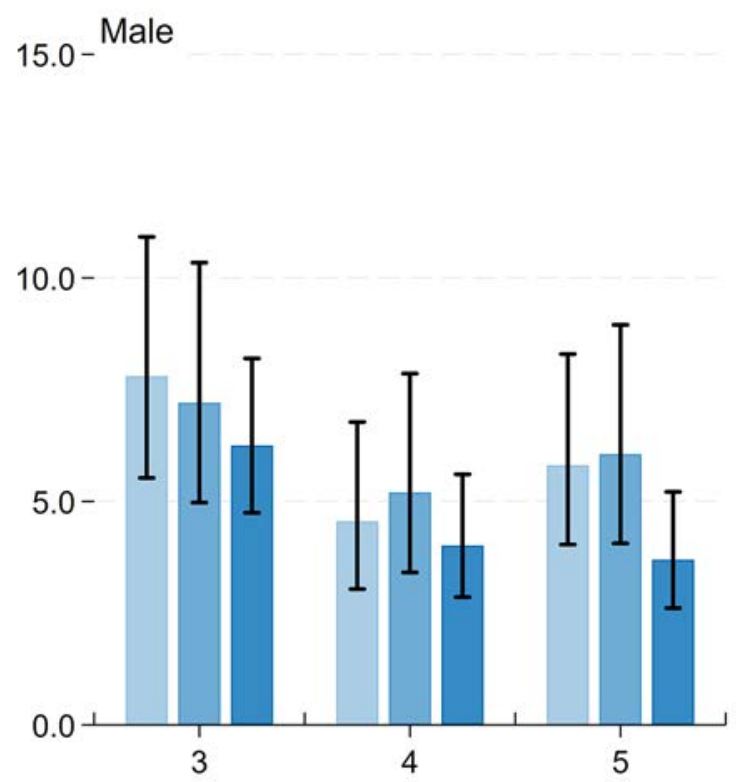

Female

$\square$ Dublin $\square$ Other urban $\square$ Rural

$\square$ Dublin $\square$ Other urban $\square$ Rural

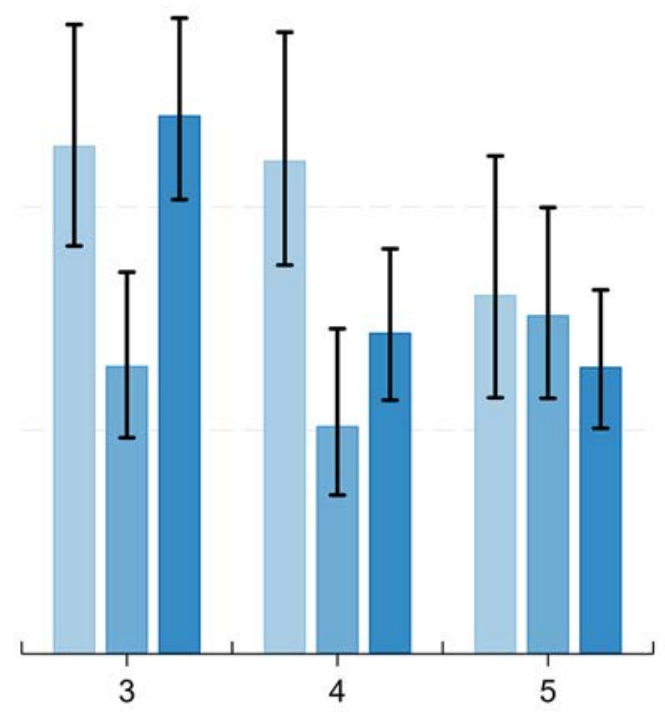

Reported caring also varies by educational attainment, although this difference is only seen in women. Women with tertiary level education were more likely to report caring in Wave 5 (10\%) although this proportion decreased from 12\% in Wave 3, compared to women with primary education (5\%), while the proportion who report caring in those with primary education remained the same between 2014 and 2018. For men, while caring didn't vary by educational attainment, there was a decreasing trend in men with tertiary education reporting caring between Wave 3 and Wave 5 , from $8 \%$ to $5 \%$ while no decrease was seen in men with primary education, remaining at $5 \%$ in Wave 5 (Figure 3.5). 
Figure 3.5. Prevalence of caring by educational attainment and sex

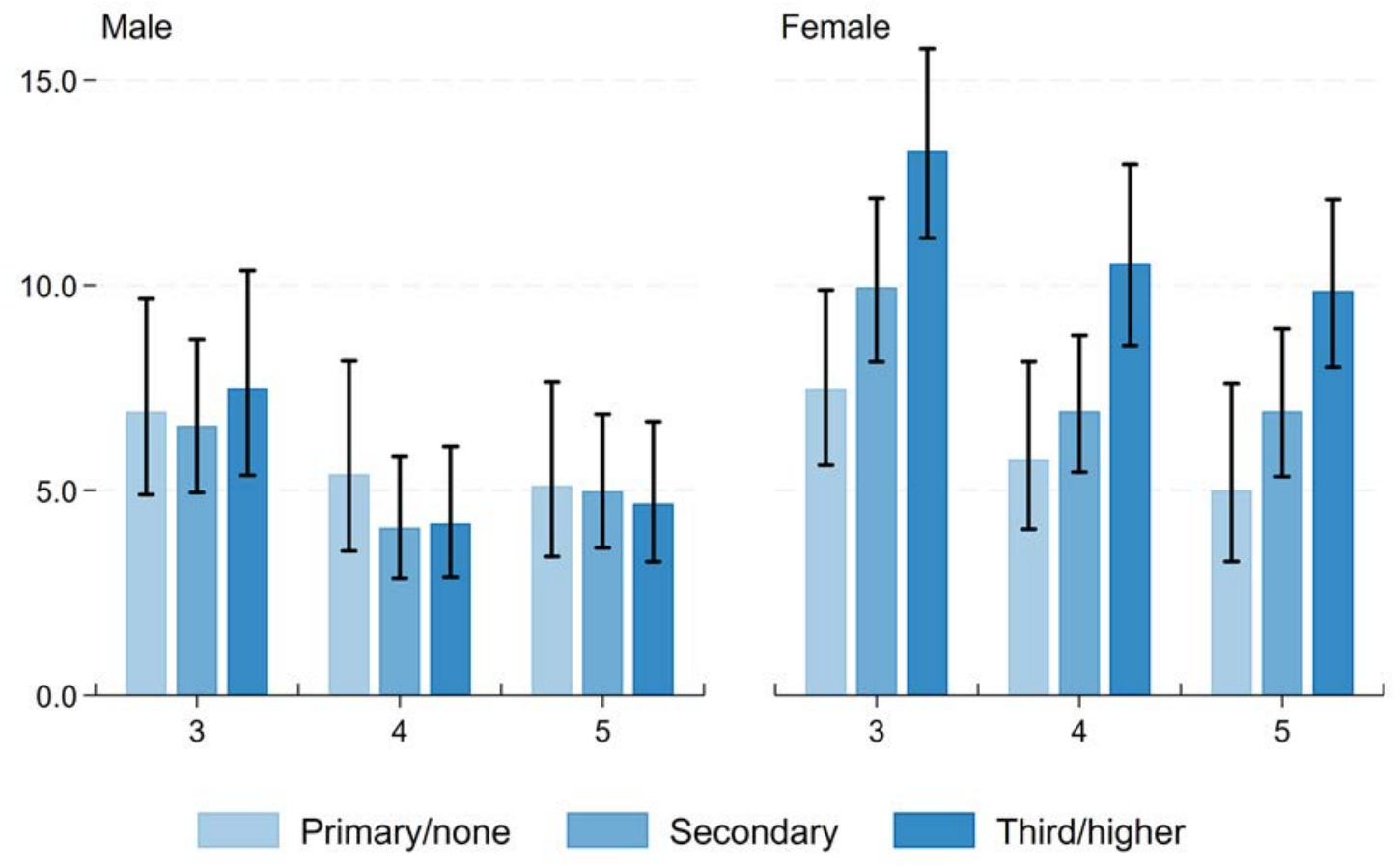

\subsection{Numbers of hours of caring provided}

We asked participants who said they had cared for someone in the past week how many hours of care they had provided. The number of hours varies and was mainly low (Wave 3 median 14, range 5-40 and Wave 5 median 20, range 6-84), with a small proportion providing more than 50 hours of caring in the past week. However, while the proportion of women who report caring in the last week decreased between Wave $3(7 \%)$ and Wave $5(5 \%)$, the proportion who report caring for more than 50 hours remained the same at 2\% (Figure 3.6a \& Figure 3.6b). Women with tertiary level education are more likely to report caring between 1-49 hours in the last week (7\%) compared to women with primary education (3\%) in Wave 3, and also in Wave 5 (4\% versus $2 \%$ ). 
Figure 3.6a. Prevalence of hours of caring in the last week for those who provide care by sex and educational attainment, Wave 3 to Wave 5

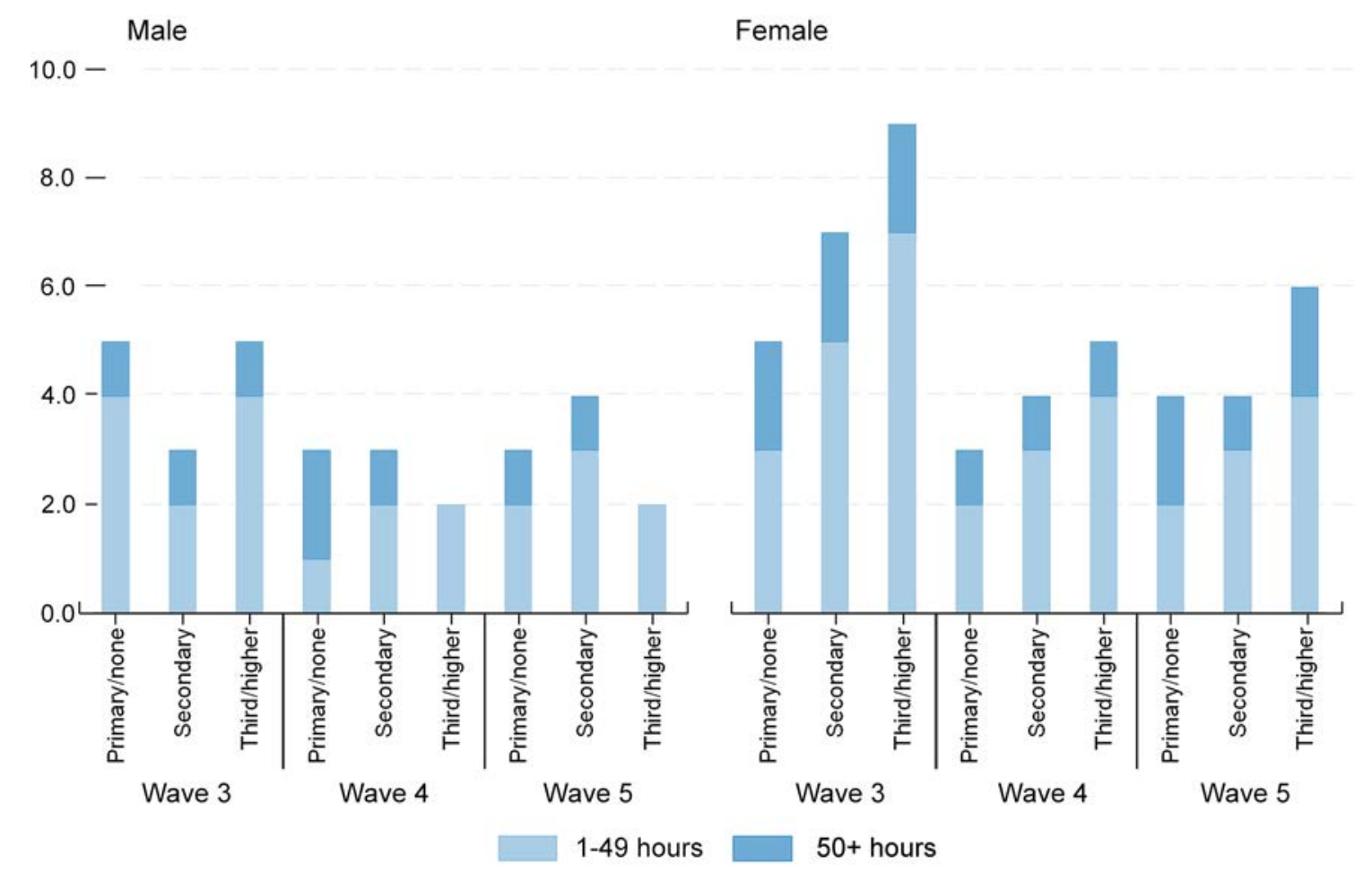

Figure 3.6b. Prevalence of hours of caring in the last week for those who provide care by sex and age group, Wave 3 to Wave 5
Male
Female

$10.0-$

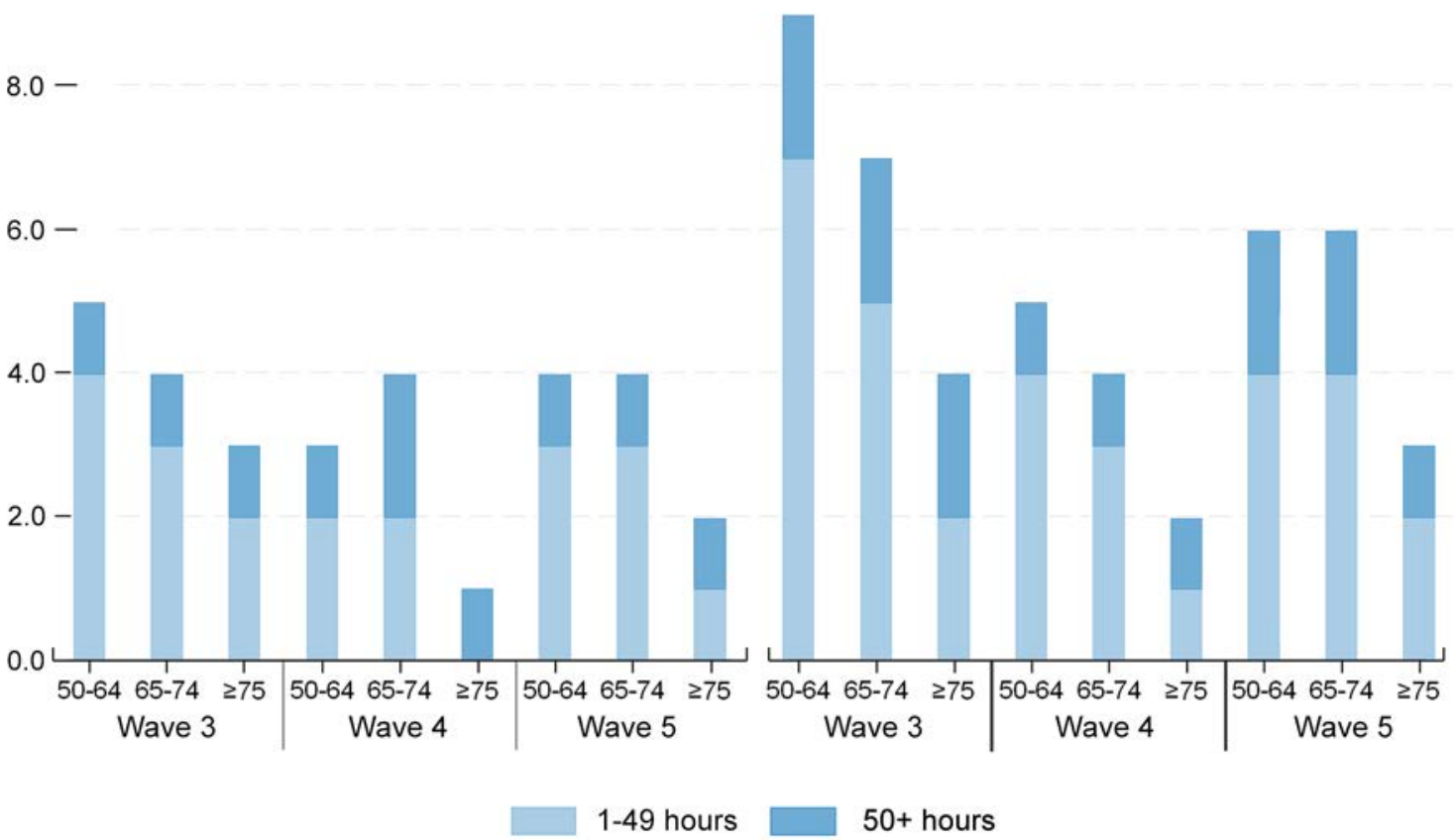




\subsection{Relationship to the care recipient}

We also asked those who were providing care what their relationship was to the care recipient. In Wave 3, 37\% reported that the main recipient for whom they were providing care was another relative; a further $23 \%$ reported it was their spouse, while $19 \%$ report giving care to a friend or neighbour (Figure 3.7). In wave 5, 33\% of care was given to another relative, $28 \%$ to a spouse and $10 \%$ to a friend or neighbour. These proportions were similar for men and women.

Figure 3.7. Care recipient for those providing caring Wave 3 to Wave 5

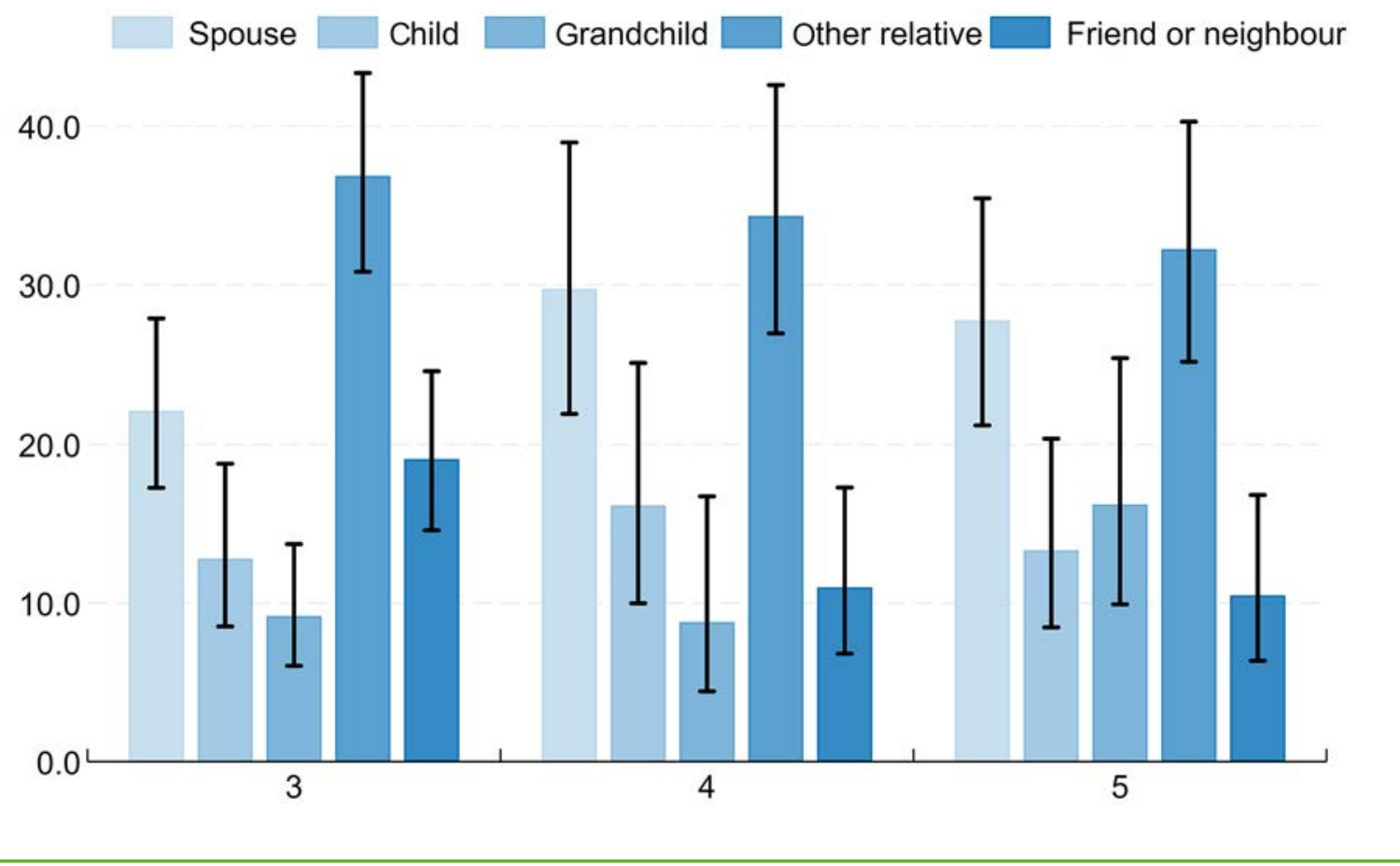

The distribution of the relationship to the care recipient differs by the age of the carers. Figure 3.8 shows that carers aged 50-64 years are more likely to report the care recipient was another relative (49\% in Wave 5) than their spouse (19\%). This compares to adults aged 75 years and over, who report the main care recipient was their spouse (38\%), while $17 \%$ care for another relative and $18 \%$ for a friend or neighbour. 
Figure 3.8. Care recipient for those providing caring by age, Wave 5

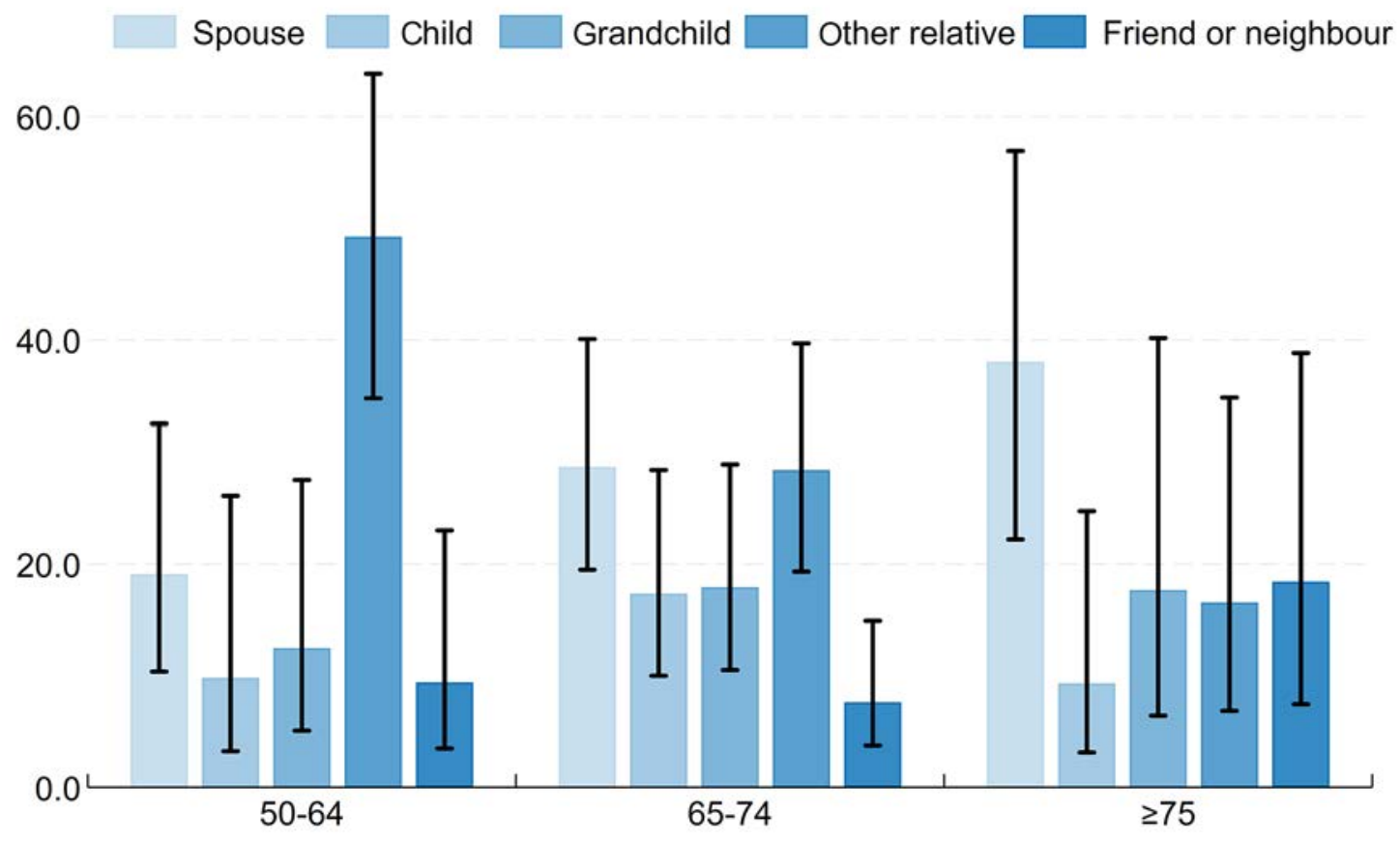




\section{Family caring and the health of carers}

We examine health and wellbeing outcomes by caring status and numbers of hours of caring to determine if the health of carers is different from non-carers.

\subsection{Caring and wellbeing}

In TILDA, depressive symptomology is assessed using the 8-item version of the Centre for Epidemiological Studies-Depression (CESD8) scale $(19,20)$. This validated measurement tool captures the frequency that participants have experienced a variety of depressive symptoms within the past week. The total number of positive and negative responses to the eight statements are summed to give a total CES-D 8 score (range 0 to 24), with higher scores indicating increased depressive symptomology.

Figure 4.1. Prevalence of CESD depressive symptomology by family caring intensity

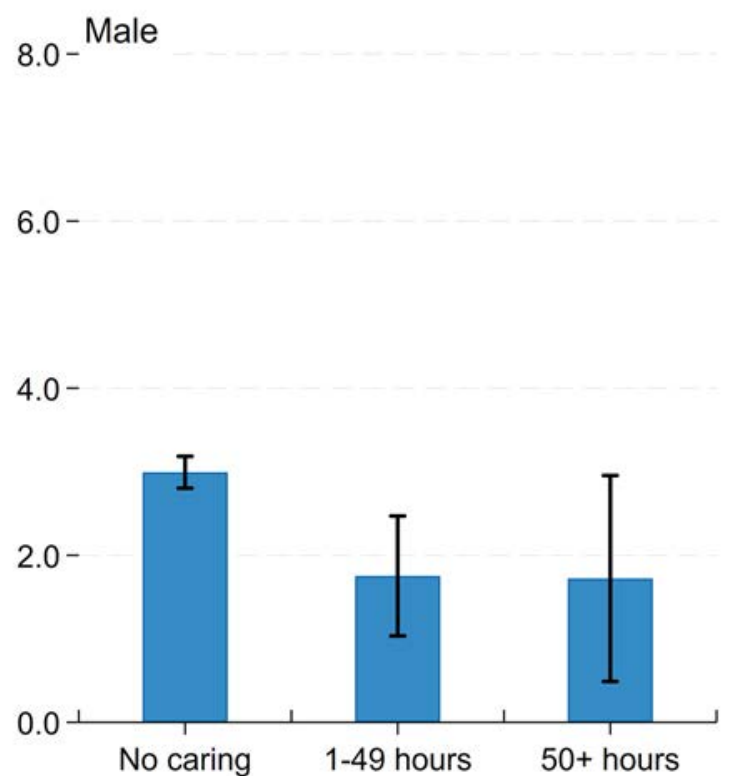

Mean CESD Score
Female

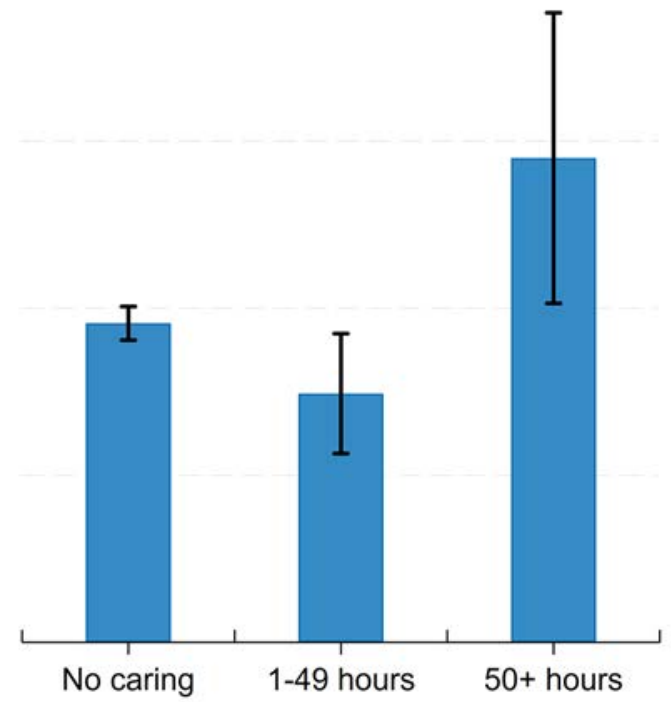

95\% Confidence Interval

Figure 4.1 shows that the prevalence of depressive symptoms was lower in men who took part in any caring in the last week relative to men who did not, 1.24 points and 1.27 points respectively for 1-49 hours and 50 or more hours. A different trend was seen in women who reported caring; women who report between 1-49 hours of caring had lower CES-D 
scores than those who report no caring. Depressive symptoms were higher in those reporting more than 50 hours of caring in the last week for women, with a mean CES-D score of 5.8 relative to 3.2 for those women providing between 1-49 hours and 3.8 for women who report no family caring (higher score more depressed).

TILDA uses the 12-item self-report measurement, CASP-12, to assess quality of life in Wave 5 (14). The scale covers the four domains (Control, Autonomy, Self-realisation, Pleasure) considered to encompass quality of life. The items included in CASP-12 consist of statements such as: 'I can do the things I want to do', 'I look forward to every day' and 'I feel that life is full of opportunities'. These statements are presented to participants in the SCQ, and they are asked to indicate how often (often, sometimes, not often or never) they feel each statement applies to their life. Each item is summed to give an overall score (range 0 to 36), with higher scores denoting better quality of life.

Figure 4.2. Mean Quality of life score (CASP-12) by family caring and sex, Wave 5

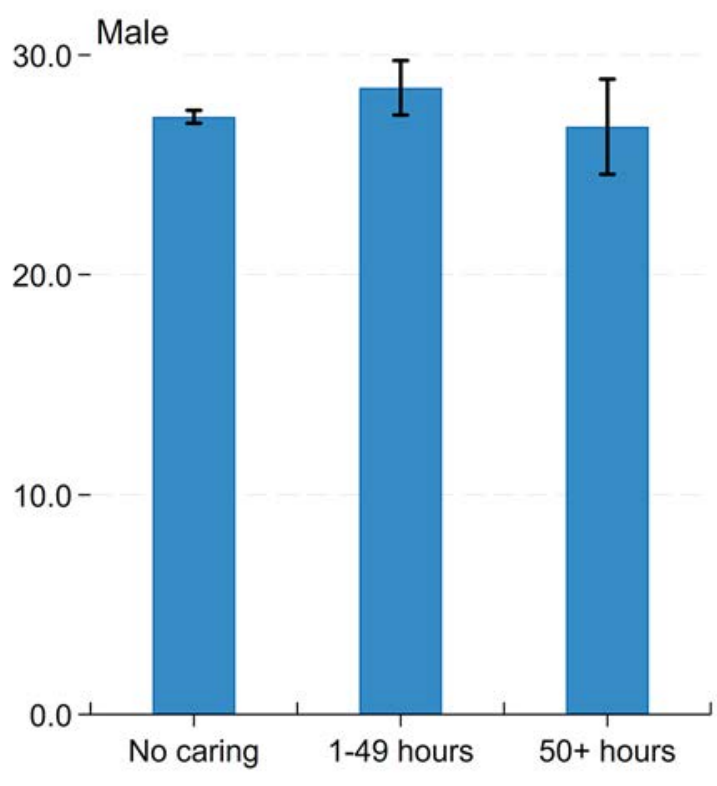

$\square$ Mean CASP-12 Score
Female

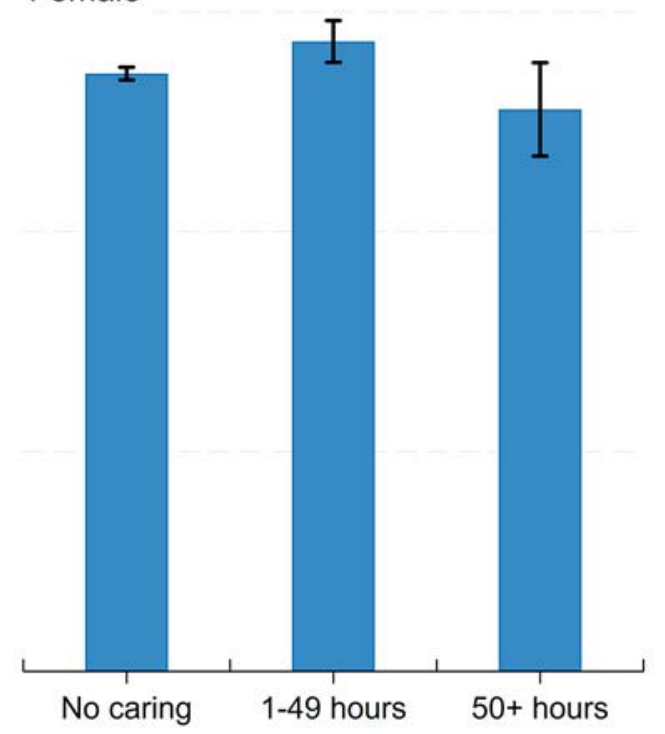

95\% Confidence Interval

Quality of life is high for participants, with an average score of 27.3 (sd 5.1) in Wave 5 (Figre 4.2). This is consistent for men regardless of caring status. However, quality of life score was lower in women who report 50 or more hours of family caring in the last week (1.63 CASP-12 points lower than women who report no caring), while quality of life was higher for women who report between 1 to 49 hours relative to those who reported no caring (higher score indicates better quality of life). 


\subsection{Caring and self-rated health}

Participants were asked to self-rate their health relative to other people their own age: In general, compared to other people your age, would you say your health is: excellent, very good, good, fair or poor?" This was grouped as excellent or very good, good, and fair or poor.

Figure 4.3. Self-rated health by family caring and sex, Wave 5

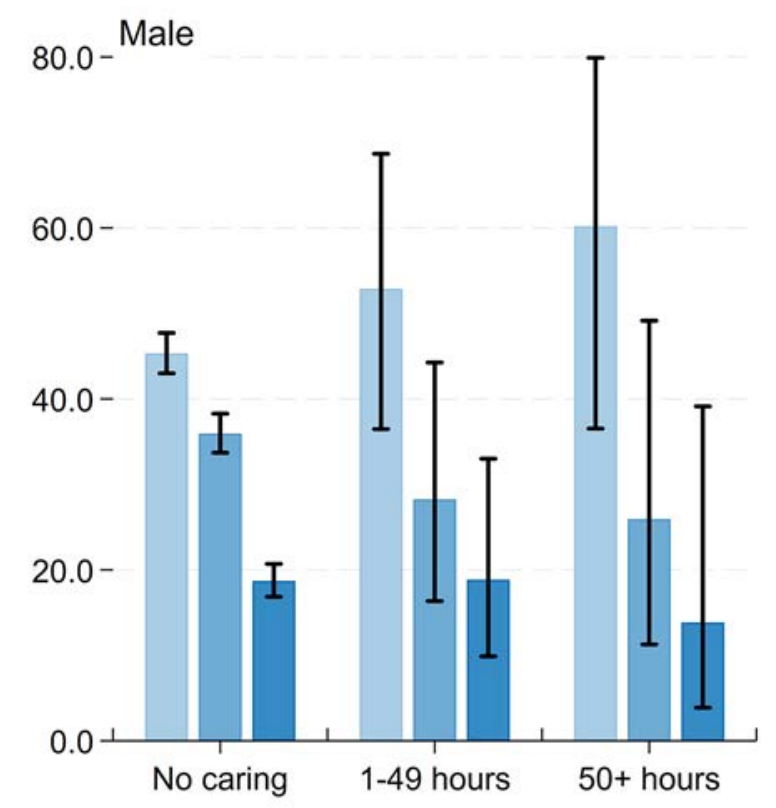

Female

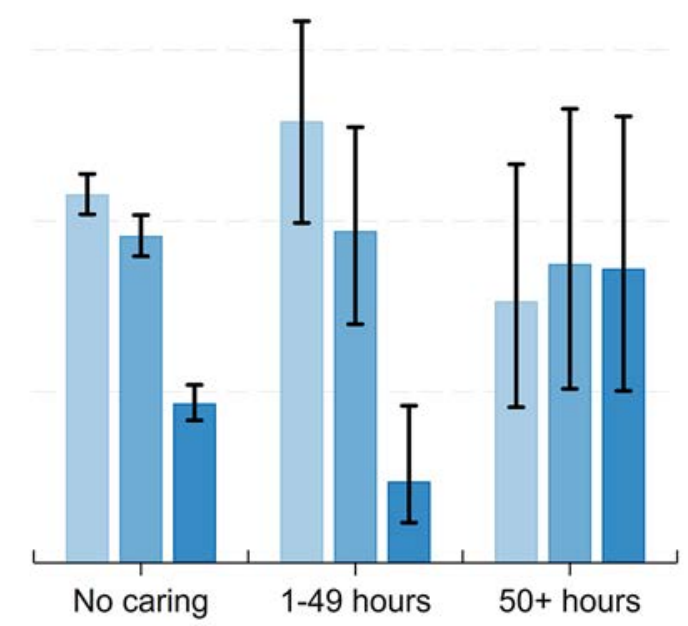

Excellent/very good

Good

Fair/poor

A high proportion of adults aged 50 years and over rate their health as good, or very good or excellent (81\%) and this is consistent for men regardless of family caring status. Figure 4.3 shows that women who report providing 50 or more hours of family caring are less likely to report their health as excellent or very good (66\%). Women who report between 1 to 49 hours are more likely to report their health as very good or excellent (90\%) and less likely to report their health as poor (10\%) than either women who provide no care $(19 \%)$ and women who provide more than 50 hours (34\%).

\subsection{Caring and chronic pain}

Pain is one of the most common reasons for disability in older adults and is associated with immobility, poorer health status and greater healthcare utilisation $(17,18)$. Research from Care Alliance Ireland examining the health status of family carers found that family 
carers reported comparatively high levels back pain (6). In a 2019 survey of family carers in Ireland, 40\% of respondents reported back injury; this was up from 33\% in a 2009 survey (19). In TILDA, information about chronic back pain is collected as part of the CAPI, and participants are asked if they have pain that has lasted for more than 3 months.

Figure 4.4. Prevalence of chronic back pain by family caring intensity and sex, Wave 5

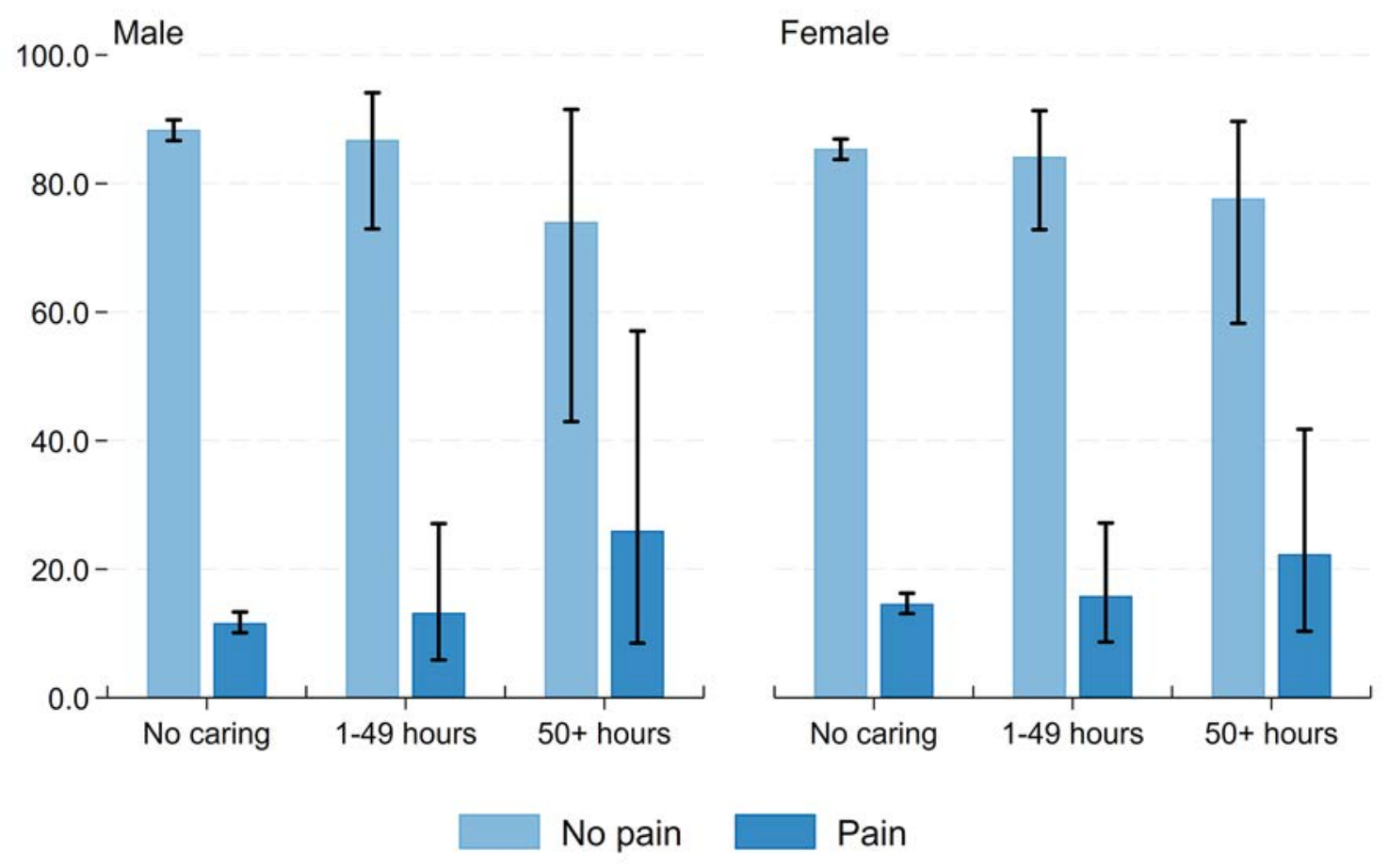

Overall, $13 \%$ of participants report chronic back pain in Wave 5; there is no difference in back pain in those reporting more than 50 hours caring in the last week (24\%) compared to $1-49$ hours $(15 \%)$ or no caring (13\%). There are also no differences by gender (Figure 4.4$)$. Overall, $12 \%$ of men and $15 \%$ of women report chronic back pain, and this was consistent regardless of caring status.

\subsection{Caring and sleep disturbance}

Sleep is known to be important for maintaining health and wellbeing and continues to remain important as we age (20). A report based on a survey of family carers in Ireland, most of whom had a high care burden (82\% caring for $50+$ hours per week) showed $62 \%$ of these carers regularly got up during the night to provide care (19). We ask participants how often they have trouble falling asleep, and how often they have trouble with waking up too early and not being able to fall back asleep again, to estimate sleep disturbance. Overall, $64 \%$ report that they rarely or never have trouble falling asleep, while $26 \%$ report 
they sometimes have trouble, and $10 \%$ report they have trouble falling asleep most of the time. Women are more likely to report having trouble falling asleep sometimes or most of the time than men. There is no evidence that carers are more likely to have trouble with falling asleep than non-carers (Figure 4.5).

Figure 4.5. Proportion of carers who experienced trouble falling asleep by caring intensity and sex, Wave 5

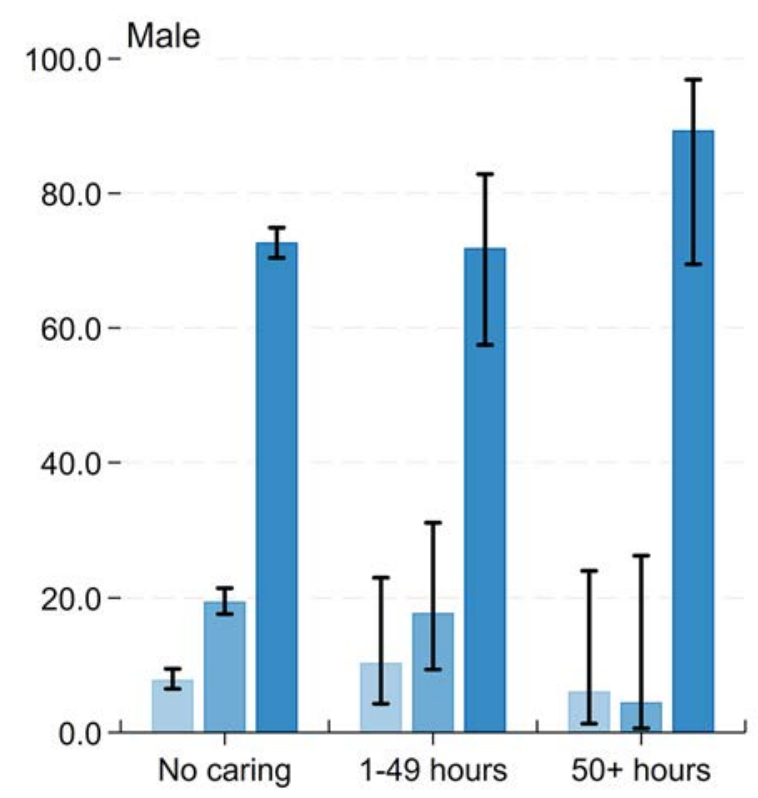

Female

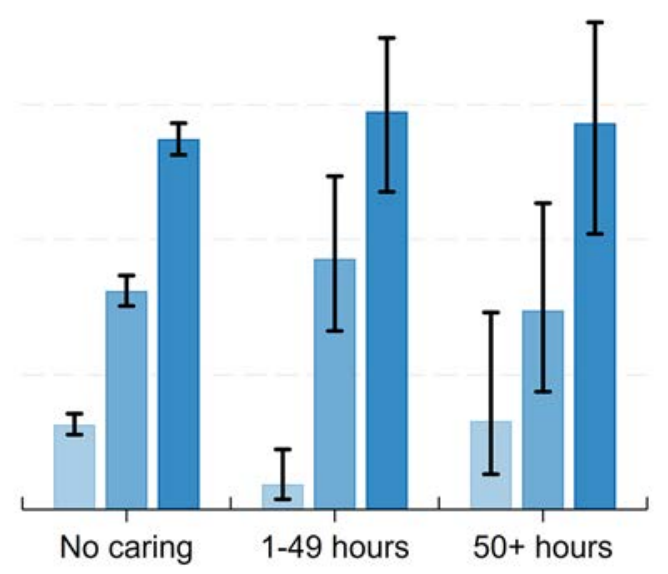

Most of the time

Sometimes

Rarely or never

A similar distribution was seen for those who report having trouble with early waking. Overall, 51\% report rarely or never having trouble with early waking; 33\% report they sometimes have trouble with early waking; and $16 \%$ report they have trouble with early waking most of the time. Figure 4.6 shows that women are more likely to report trouble with early waking sometimes or most of the time than men, and that this didn't vary by caring status. 
Figure 4.6. Proportion of carers who found they were waking early by caring intensity and sex, Wave 5

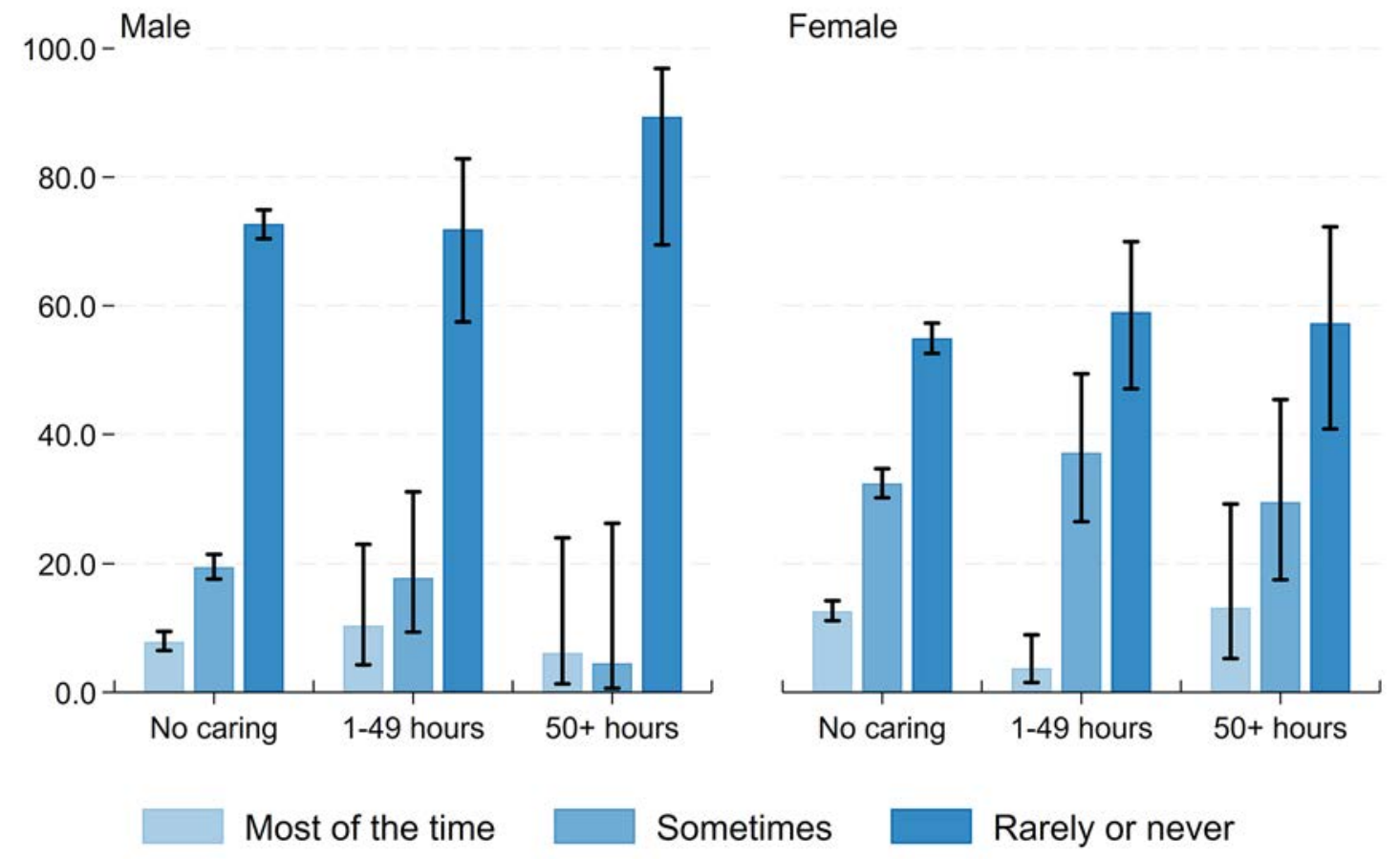

\subsection{Caring and hypertension}

Several studies have reported caring is associated with higher blood pressure, although the literature is conflicting $(6,21)$. In TILDA, hypertension was identified from either self-reported doctor diagnosis of high blood pressure or regular use of antihypertensive medications. Hypertension is common in this group (44\%), but it is relatively consistent across carers and non-carers. However, there is a trend for hypertension prevalence to be higher in men who have provided caring for 50 hours or more in the last week (66\%) compared to lower hours (39\%) or no caring (45\%); see Figure 4.7. 
Figure 4.7. Prevalence of hypertension by caring hours and sex, Wave 5

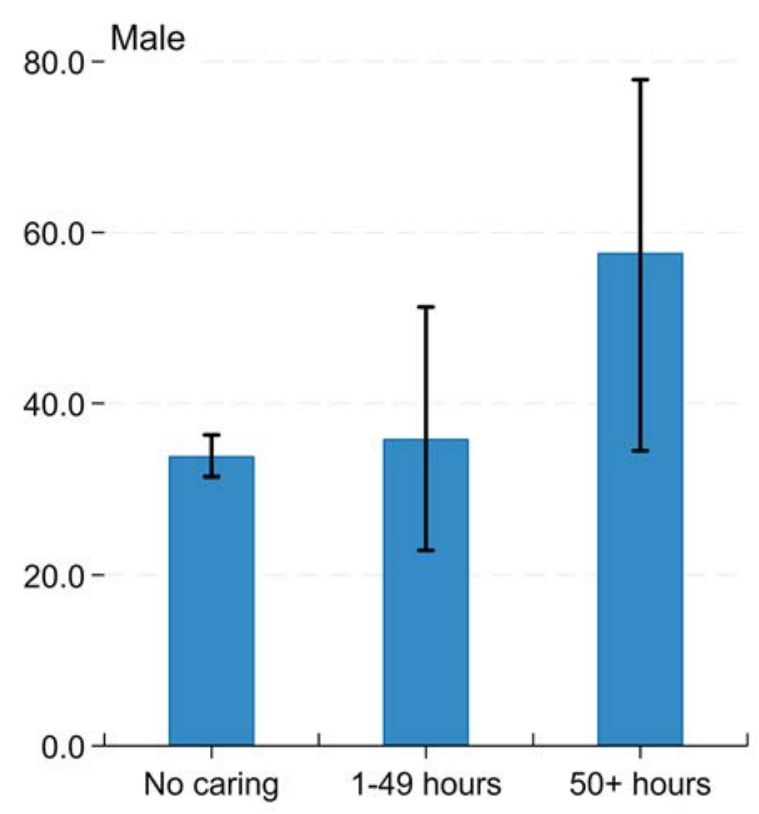

Prevalence of hypertension
Female

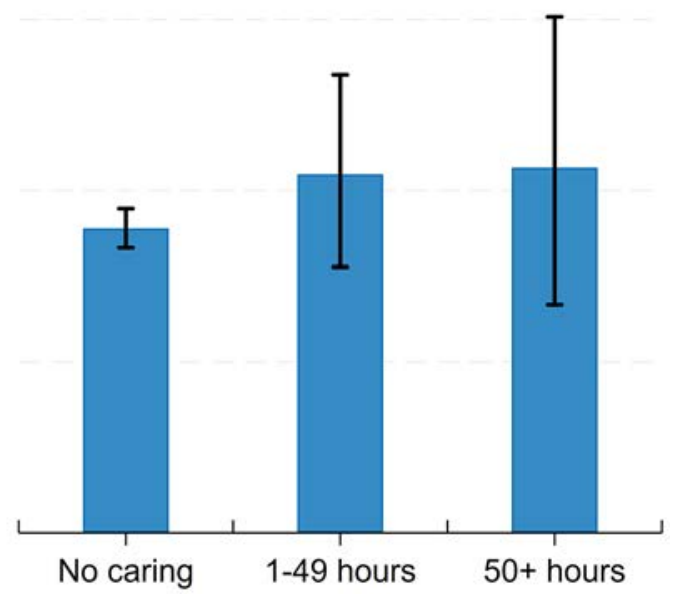

\subsection{Caring and physical function}

To assess physical function, participants were asked to complete the Timed Up-and-Go (TUG) test. TUG is a functional mobility test; participants start in the seated position and are asked to stand up, walk to a line marked 3 metres away on the floor, turn around, walk back to the chair and sit down again. The time taken to complete this task is recorded using a stopwatch. Declines in this objective measure of physical function are associated with an increased risk of outcomes such as disability, cognitive decline, hospitalisation and mortality.

Family carers have a slightly faster TUG than those adults who do not report family caring (Figure 4.8). This difference was seen only in women who report caring in the last month (10.5 seconds versus 12.2), although this is not a substantial difference in performance. These differences increased when numbers of hours were considered, and again for men, any caring was associated with faster TUG speed, (10.35 for 1 to 49 hours and 10 seconds for 50 hours or more versus 11.4 seconds for men reporting no caring). For women, lower hours of caring is associated with faster TUG speed ( 9.8 seconds versus 12.2 seconds for no caring), but women who report more than 50 hours of caring have slower speeds and are similar to the no caring group (11.5 seconds). 
Figure 4.8. Timed-up-and-go speed (secs/m) by hours of family caring and sex, Wave 5

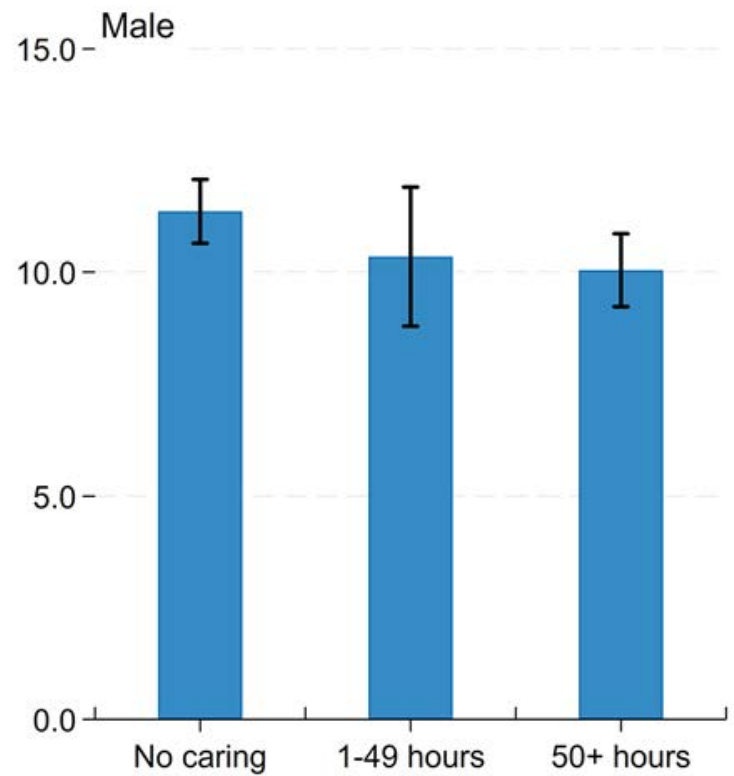

\section{Female}

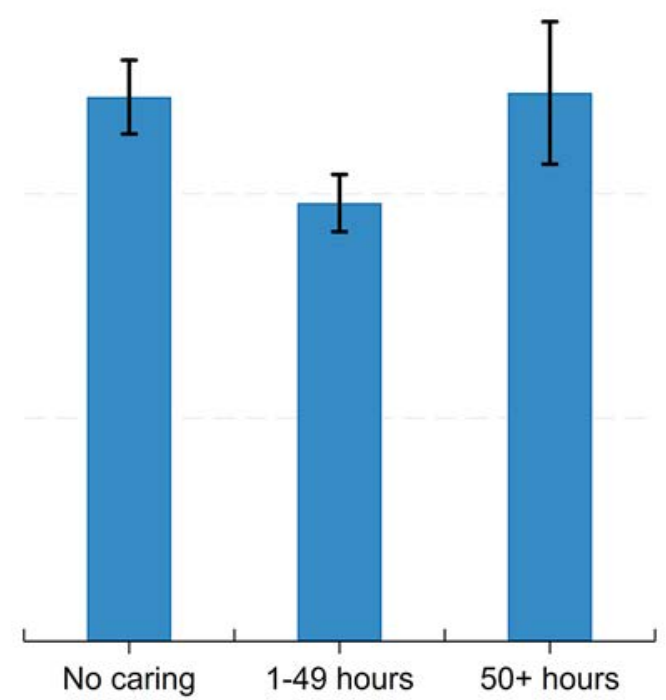

Timed-up-and-go speed (secs/m)

$\longmapsto 95 \%$ Confidence Interval 


\section{Conclusions}

This report shows that in Wave 5, 8\% of community-dwelling adults aged 50 years and older in Ireland receive care, with $7 \%$ receiving formal state or private-provided services and $7 \%$ reporting being cared for by a family member. ADL and IADL limitations increased with age and the proportion of women aged 75 years and older receiving help with ADL and IADL limitations increased from 56\% in Wave 1 to $78 \%$ in Wave 5 while the corresponding proportions for men aged 75 years and older were from $36 \%$ to $56 \%$. For those with any ADL or IADL limitation, $36 \%$ are cared for by a family member, and a further $3 \%$ are cared for by non-relatives and $16 \%$ by paid carers. Help with IADL limitations is predominantly provided by family carers for both men and women. ADL care has become increasingly provided by non-relative carers, the majority of whom were paid carers, and in Wave 5 half of ADL care was provided by non-relative carers, $80 \%$ of whom were paid carers and $20 \%$ by unpaid non-relatives, probably a friend or neighbour. However, most older adults living with a functional limitation receive a combination of family caring and formal state or privately provided caring, although there was some regional variation in receipt of support for functional limitations, with older people in Dublin city and county less supported than their counterparts in rural areas or other urban and cities.

We confirm the finding that the older population contribute substantially to the informal care of their family and friends. Overall, $7 \%$ of women and $5 \%$ of men aged 58 years and older report they are a carer to family and friends in Wave 5. This equates to 68,500 people nationally. Generally, family caring was associated with positive health outcomes, but this depended on the intensity of caring provided. Compared to non-carers, women providing low intensity caring (up to 49 hours per week) reported better self-rated health and wellbeing (higher quality of life score), lower depressive symptoms, and higher functional mobility. However, women reporting more than 50 hours of caring in the last week report higher depressive symptoms, lower quality of life, more chronic pain, and lower functional mobility measured by TUG. Men who were carers did not for the most part show differences in health, except for lower depressive symptoms in men who provided any caring, and increased hypertension in men providing more than 50 hours of caring.

This supports previous research which showed that carers are healthier and demonstrate better mood than non-carers $(22,23)$. There is strong evidence supporting the health benefits of remaining physically and socially active, which caring at lower numbers of hours 
may facilitate. These benefits were mainly seen for women, but so were the detrimental effects of caring at high intensity, for both physical health and wellbeing including lower quality of life and higher depressive symptoms. Research has suggested that caring for a spouse may in itself lead to cognitive decline in the carer through psychosocial (e.g., depression, loneliness, social isolation, sleep problems), and behavioural (e.g., exercise, diet) mechanisms, risk factors which are all modifiable and may compromise the lives of the spousal carers and their ability to function (24). Carers' stress and depression has also been found to be independently associated with developing cardiovascular disease longitudinally in family carers for people with dementia (25), and spousal caring has been associated with incident cardiovascular disease in the US (26). Further research is needed to clarify mechanisms of resilience and support that may improve the detrimental healthrelated risks of caring.

The proportion of caring received from a paid non-relative, or formal care provision, has increased as our cohort has aged. This may be an indication of worsening health, or of increased availability of home support. It may also be an indication of reduced capacity for a spouse to provide care, which may be reflected in the decrease in spouses providing family caring. Many studies find that the use of formal care services is associated with higher disability $(27,28)$ and with living alone without an informal carer $(29)$, and that when informal care is available, this may delay the provision of formal care services (30). Family carers allow both a significant reduction in expenditure on state-provided home care and institutional care for older people, and impact positively on the health of the care recipient who remains at home with loved ones. Support is needed to enable family carers to continue in their role for as long as possible, and the drive to help people remain at home must be supplemented with formal home care support. Support can include home care hours by state-provided workers; respite to allow the carer to engage in other activities; and financial support. Recent reviews of available interventions for carers of persons with dementia found that interventions have focussed on social support groups and cognitive behaviours therapy to cope with problematic behaviours in spouses. These have included mindfulness-stress reduction techniques for improving overall mental health and reducing stress and depression (31).

One of the main strengths of this study was the use of a large representative sample of older adults with health and wellbeing outcomes including an objective measure of physical function. There are some limitations to our study, which should be noted. Caring is self-reported, and many be underestimated as family carers may not perceive caring for their spouse or older parents as caring, but just part of normal family interactions. We also have not examined the duration of caring, which would likely also be associated with 
health outcomes (32). There may also be a selection bias associated with healthier people becoming carers, and this might be particularly relevant in the Irish context, where nursing home placement is more common.

In summary, this study describes the characteristics of both care recipients and carers in the older population in Ireland, and health outcomes associated with caring. We find that there are positive health outcomes associated with lower hours of family caring. However, high hours of caring are associated with poor health and wellbeing outcomes, particularly for women. Future research should investigate if there is a threshold amount of state and private care necessary to reduce carer burden. As state-provided care should allow more leisure time for informal carers, a better understanding of the determinants that contribute to the allocation of formal care services for carers is also essential. Country-specific policy responses to population ageing require identification of these differences between formal care use and family caring at the population level; and an understanding of why they exist, particularly if these differences are driven by socioeconomic factors. Overall, our findings suggest interventions to increase social inclusion of family carers and enhance home support through formal care mechanisms should reduce these negative effects on the wellbeing and health of carers and will be important for future public health (33). To encourage family caring, state-provided home support must also be available to facilitate and support carers to retain their work and leisure in addition to their caregiving. This will help ensure the carer's journey remains positive and will enable both the carer and the care recipient to remain in the home for as long as is possible 


\section{References}

1. World Health Organization. World report on ageing and health. Geneva; 2015.

2. United Nations, Affairs. DoEaS, Division. P. World Population Prospects: The 2017 Revision, Volume 1: Comprehensive Tables. ST/ESA/SERA/400. 2017.

3. Roe L, Thomas S, Trepel D, Normand C. Trends in healthcare cover and healthcare use for older adults in Ireland during the austerity years of 2009 to 2016. In: Turner N, Donoghue OA, Kenny RA, editors. Wellbeing and Health in Ireland's over 50s 20092016. Dublin: The Irish Longitudinal Study on Ageing; 2018.

4. Roe L, McGarrigle CA, Hernandez B, O'Halloran A, Scarlett S, Ward M, et al. Patterns of health service utilisation: Results from Wave 5 of The Irish Longitudinal Study on Ageing. Dublin; 2020.

5. Morley JE. Aging in place. Journal of the American Medical Directors Association. 2012;13(6):489-92.

6. Care Alliance Ireland. Health and Wellbeing of Family Carers in Ireland: Results of a survey of recipients of the Carer's Allowance. Dublin; 2008.

7. Roth DL, Perkins M, Wadley VG, Temple EM, Haley WE. Family caregiving and emotional strain: associations with quality of life in a large national sample of middleaged and older adults. Quality of life research : an international journal of quality of life aspects of treatment, care and rehabilitation. 2009;18(6):679-88.

8. Ho SC, Chan A, Woo J, Chong P, Sham A. Impact of caregiving on health and quality of life: a comparative population-based study of caregivers for elderly persons and noncaregivers. The journals of gerontology Series A, Biological sciences and medical sciences. 2009;64(8):873-9.

9. McGarrigle CA, Cronin $\mathrm{H}$, Kenny RA. The impact of being the intermediate caring generation and intergenerational transfers on self-reported health of women in Ireland. International journal of public health. 2014;59(2):301-8. 
10. Wolff JL, Dy SM, Frick KD, Kasper JD. End-of-life care: findings from a national survey of informal caregivers. Archives of internal medicine. 2007;167(1):40-6.

11. Cheng ST, Mak EP, Lau RW, Ng NS, Lam LC. Voices of Alzheimer Caregivers on Positive Aspects of Caregiving. The Gerontologist. 2016;56(3):451-60.

12. McMunn A, Nazroo J, Wahrendorf M, Breeze E, Zaninotto P. Participation in sociallyproductive activities, reciprocity and wellbeing in later life : baseline results in England. Ageing \& Society. 2009;29:765-82.

13. Perkins M, Howard VJ, Wadley VG, Crowe M, Safford MM, Haley WE, et al. Caregiving strain and all-cause mortality: evidence from the REGARDS study. The journals of gerontology Series B, Psychological sciences and social sciences. 2013;68(4):504-12.

14. O'Reilly D, Connolly S, Rosato M, Patterson C. Is caring associated with an increased risk of mortality? A longitudinal study. Social science \& medicine (1982). 2008;67(8):1282-90.

15. O'Reilly D, Rosato M, Ferry F, Moriarty J, Leavy G. Caregiving, volunteering or both? Comparing effects on health and mortality using census-based records from almost 250,000 people aged 65 and over. Age and ageing. 2017;46(5):821-6.

16. Donoghue OA, McGarrigle CA, Foley M, Fagan A, Meaney J, Kenny RA. Cohort Profile Update: The Irish Longitudinal Study on Ageing (TILDA). International journal of epidemiology. 2018;47(5):1398-I.

17. McGarrigle CA, Donoghue OA, Scarlett S, Kenny RA. Health and Wellbeing: Active ageing for Older Adults in Ireland. Dublin; 2017.

18. Kennedy N, O'Sullivan K, Hannigan A, Purtill H. Understanding pain among older persons: Part 2-the association between pain profiles and healthcare utilisation. Age and ageing. 2017;46(1):51-6.

19. Family Carers Ireland, College of Psychiatrists Ireland, University College Dublin. Paying the Price: The Hidden Impacts of Caring. Dublin; 2019.

20. Scarlett S, Nolan H, Kenny RA, O'Connell MD. Objective Sleep Duration in Older Adults: Results From The Irish Longitudinal Study on Ageing. Journal of the American Geriatrics Society. 2020;68(1):120-8. 
21. Mausbach BT, Romero-Moreno R, Bos T, von Kanel R, Ziegler MG, Allison MA, et al. Engagement in Pleasant Leisure Activities and Blood Pressure: A 5-Year Longitudinal Study in Alzheimer Caregivers. Psychosom Med. 2017;79(7):735-41.

22. Beach SR, Schulz R, Yee JL, Jackson S. Negative and positive health effects of caring for a disabled spouse: longitudinal findings from the caregiver health effects study. Psychol Aging. 2000;15(2):259-71.

23. Freedman VA, Cornman JC, Carr D. Is spousal caregiving associated with enhanced well-being? New evidence from the panel study of income dynamics. The journals of gerontology Series B, Psychological sciences and social sciences. 2014;69(6):861-9.

24. Vitaliano PP, Murphy M, Young HM, Echeverria D, Borson S. Does caring for a spouse with dementia promote cognitive decline? A hypothesis and proposed mechanisms. J Am Geriatr Soc. 2011;59(5):900-8.

25. Mausbach BT, Patterson TL, Rabinowitz YG, Grant I, Schulz R. Depression and distress predict time to cardiovascular disease in dementia caregivers. Health Psychol. 2007;26(5):539-44.

26. Capistrant BD, Moon JR, Berkman LF, Glymour MM. Current and long-term spousal caregiving and onset of cardiovascular disease. J Epidemiol Community Health. 2012;66(10):951-6.

27. Steinbeisser K, Grill E, Holle R, Peters A, Seidl H. Determinants for utilization and transitions of long-term care in adults 65+ in Germany: results from the longitudinal KORA-Age study. BMC geriatrics. 2018;18(1):172.

28. Bonsang E. Does informal care from children to their elderly parents substitute for formal care in Europe? Journal of health economics. 2009;28(1):143-54.

29. Geerts J, Van den Bosch K. Transitions in formal and informal care utilisation amongst older Europeans: the impact of national contexts. European journal of ageing. 2012;9(1):27-37.

30. Blomgren J, Martikainen P, Martelin T, Koskinen S. Determinants of home-based formal help in community-dwelling older people in Finland. European journal of ageing. 2008;5(4):335-47. 
31. Richardson TJ, Lee SJ, Berg-Weger M, Grossberg GT. Caregiver health: health of caregivers of Alzheimer's and other dementia patients. Curr Psychiatry Rep. 2013;15(7):367.

32. Vlachantoni A, Evandrou M, Falkingham J, Robards J. Informal care, health and mortality. Maturitas. 2013;74(2):114-8.

33. Beard JR, Bloom DE. Towards a comprehensive public health response to population ageing. Lancet (London, England). 2015;385(9968):658-61. 